\title{
El MAESTRo de CAPILla ViCENTE Olmos Claver y SU APORTACION A LA MUSICA RELIGIOSA ESPAÑOLA DEL SIGLO XVIII
}

\section{THE CHAPEL MASTER VICENTE OLMOS ClAVER AND HIS CONTRIBUTION TO THE SPANISH RELIGIOUS MUSIC OF THE 18TH CENTURY}

\author{
Ángel Marzal Raga \\ Conservatorio Superior de Música "Joaquín Rodrigo" de Valencia \\ angelmarzalraga@gmail.com \\ ORCID iD: http://orcid.org/0000-0003-2159-4533
}

\section{RESUMEN}

El maestro de capilla Vicente Olmos Claver nació en Catarroja (Valencia) a mediados del siglo XVIII. Su vida y su obra han pasado prácticamente inadvertidas durante los últimos dos siglos. Sin embargo, nuestra investigación sobre el músico ha permitido reconstruir buena parte de su biografía, elaborar un estudio de su obra y recuperar buena parte de su repertorio para la música religiosa española. El presente artículo esboza los contenidos de nuestro trabajo sobre el compositor. En primer lugar, veremos que su trayectoria biográfica se inicia el año 1754 en la Catedral Metropolitana de Valencia y finaliza en el monasterio Jerónimo de Nuestra Señora de la Murta de Alzira en 1812. En ese largo camino, Vicente Olmos ejerció los magisterios de capilla del Palacio Real de Valencia y de la Santa Iglesia Catedral de Segorbe. Por otra parte, nuestro artículo detalla sucintamente las principales características estilísticas y particularidades del repertorio del maestro Olmos Claver. Su obra supone una aportación inédita a la música sacra española del siglo XVIII. Vicente Olmos cultivó distintos géneros litúrgicos, sobre todo, Salmos, Lamentaciones y Villancicos litúrgicos.

Palabras clave: Vicente Olmos, España, maestro de capilla, música religiosa, monje jerónimo, segunda mitad siglo XVIII. 


\section{ABstRaCT}

The chapel master Vicente Olmos Claver was born in Catarroja (Valencia) in the mid-18th century. Both his life and work had remained unknown for the last two hundred years. However, our research on the musician has enabled us to reveal most of his biography, to elaborate a thorough study of his work and to recover great part of his repertoire for the Spanish religious music. This article outlines the contents of our research about the composer. First of all, we will find out that his biographical career starts in 1754 in the Catedral Metropolitana de Valencia and ends in the Jerome monastery of Nuestra Señora de la Murta in Alzira in 1812. During his life, Vicente Olmos worked as chapel master not only in the Palacio Real de Valencia but also in the Santa-Iglesia Catedral de Segorbe. Furthermore, our article summarises the main stylistic characteristics and peculiarities of the repertoire by Master Olmos Claver. His work is an unpublished contribution to the Spanish sacred music of the 18th century. Vicente Olmos composed different liturgical genres, specially, Psalms, Lamentations and liturgical Villancicos.

Palabras clave: Vicente Olmos, Spain, chapel master, religious music, jerome monk, second half 18 th century.

Marzal Raga, B. (2019). El maestro de capilla Vicente Olmos Claver y su aportación a la música religiosa española del siglo XVIII. Cuadernos de Investigación Musical, 8, pp. 41-76.

\section{INTRODUCCIÓN ${ }^{1}$}

Los estudios sobre música española del siglo XVIII han permitido clarificar notablemente el panorama musical de la España dieciochesca. La musicología española ha publicado numerosos trabajos sobre dicho período, de manera que, ha cumplido unas expectativas que seguramente no contemplaba unas pocas décadas atrás. Sin embargo, aunque las diversas aportaciones investigadoras han ampliado el elenco de autores y, paralelamente, el volumen de repertorio musical conocidos, no es menos cierto que queda aún mucho por hacer en buena parte de nuestros archivos.

\footnotetext{
${ }^{1}$ Abreviaturas:

AAIE: Asociación de Archiveros de la Iglesia en España. ACAO: Associació Cabanilles d'Amics de l'Orgue.

ACPV: Archivo del Colegio del Patriarca de Valencia.

ACS: Archivo de la Santa Iglesia Catedral de Segorbe.

ACV: Archivo de la Catedral Metropolitana de Valencia.

ADV: Archivo Diocesano de Valencia.

ARV: Archivo del Reino de Valencia.

BAMV: Biblioteca del Ateneo Mercantil de Valencia.

BUV: Biblioteca Universitaria de Valencia.

CSIC: Consejo Superior de Investigaciones Científicas.

RISM: Répertoire International des Sources Musicales.
} 
Nuestra investigación sobre Vicente Olmos Claver encuentra su justificación entre estos parámetros; un autor de trayectoria prácticamente desconocida cuya producción musical ha permanecido durante siglos en la paz de los archivos. En nuestra opinión, tanto su vida como, más aún, su obra exigía un estudio pormenorizado en aras, sobre todo, de recuperar su música para las generaciones futuras.

Todo esto nos llevó a iniciar una investigación que pudimos presentar finalmente como Tesis Doctoral en la Universitat de València (Marzal, 2013). Dicho trabajo contiene un amplio estudio biográfico y también musicológico. Asimismo, también presenta una transcripción en edición crítica de parte de la música de Vicente Olmos Claver, así como, un catálogo de toda su obra redactado según normativa internacional ${ }^{2}$.

Asimismo, nuestra Tesis Doctoral ha sido publicada recientemente en dos volúmenes que recogen buena parte de sus contenidos para, en definitiva, colocar a disposición de la comunidad investigadora una nueva herramienta de estudio (Marzal, 2019). Con todo, resulta indispensable señalar que la información que expondremos en el presente artículo procede principalmente de las dos fuentes bibliográficas que acabamos de citar (Marzal, 2013 y 2019).

Vicente Olmos Claver nació en Catarroja, localidad valenciana situada muy cerca de la capital del Turia. Los trabajos bibliográficos más tempranos no ofrecen información acerca de la fecha de nacimiento de nuestro músico (Perpiñán, 1897) (Ruiz de Lihory, 1903). Sin embargo, el musicólogo José Climent nos dice en época reciente que Vicente Olmos Claver nació "hacia 1744" (Climent, 1972, p. 68). No obstante, no hemos encontrado ningún documento que certifique la fecha de nacimiento. Por una parte, los archivos parroquiales de la localidad natal de Catarroja desaparecieron con la Guerra Civil de 1936. De otra, las primeras actas del Registro Civil de Catarroja son del tercer cuarto del siglo XIX, por tanto, no recogen circunstancia alguna sobre nuestro músico (Marzal, 2019, p. 85). Con todo, veremos seguidamente que Vicente Olmos Claver inició su trayectoria musical en la Catedral Metropolitana de Valencia. Según el musicólogo Antonio Gallego, "la edad ideal de los niños para el ingreso era la de diez años" (Gallego, 1988, p. 129). Efectivamente, la documentación que hemos cotejado en la Catedral Metropolitana de Valencia confirma que los cantores se iniciaban como "infantillos" entre los siete y los diez años ${ }^{3}$. De acuerdo con todo esto, podemos aceptar 1744, sin precisar fecha concreta, como año aproximado de nacimiento de Vicente Olmos Claver.

\footnotetext{
2 (RISM, 1996). Vid. (Marzal, 2013, pp. 661-830) (Marzal, 2019, pp. 585-750).

3 (ACV): 2926 Oposiciones, A Beneficio con carga especial 463-15, (s.f.r.). Vid. (Marzal, 2019, p. 87). 


\section{Vicente Olmos Claver en la Catedral Metropolitana de Valencia}

El archivo de la Catedral Metropolitana de Valencia contiene un documento que certifica que Vicente Olmos comenzó a cantar como "infantillo" de la capilla de música de dicha Catedral en 1754:

Vicent Olmos. Vicent Olmos natural de Catarroja fill de Vicent Olmos, y de Francisca Claver Coniugues. Comensà â Cantar en 12 de Dehembre 1754. Segons relacío del Mestre de Capella.

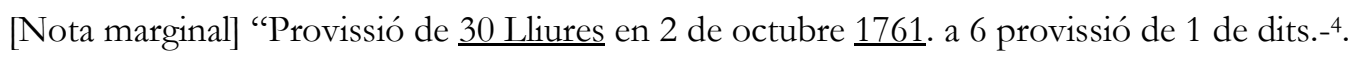

Como podemos comprobar, este documento certifica que efectivamente Vicente Olmos era natural de la Villa de Catarroja. Además, nos proporciona la identidad de sus padres; Vicente Olmos y Francisca Claver. Por nuestra parte, también nos hemos ocupado de comprobar las funciones realizadas por la capilla de música de la Catedral de Valencia el citado día 12 de diciembre de 1754. Con toda probabilidad, Vicente Olmos Claver inició su andadura con la Capilla Metropolitana cantando un Oficio de Maytines; según la documentación capitular un Ofici a la Inmaculada Concepció. Con todo, uno de los aspectos más interesantes del documento es que está validado por el maestro de capilla. En este sentido, el documento certifica que nuestro Vicente Olmos comenzó su formación musical bajo la tutela del maestro de capilla de la Catedral Metropolitana de Valencia José Pradas Gallén; uno de los grandes músicos que ocuparon el magisterio de la Metropolitana de Valencia en el siglo XVIII.

Más adelante, siguiendo el orden jerárquico de las capillas eclesiásticas del siglo XVIII, Vicente Olmos Claver fue nombrado Moso de Capella en la Catedral Metropolitana de Valencia. El nuevo nombramiento comportaba la adquisición de nuevas obligaciones que, de hecho, contaban con la correspondiente remuneración económica. Además, los Mosos continuaban su formación en la Catedral y, por supuesto, seguían cantando en los Oficios y funciones de la capilla de música. Según nos dicen algunas fuentes, Vicente Olmos conservó la voz largos años (Climent, 1984, p. 184), razón que nos induce a pensar que efectivamente estaba en condiciones de cumplir con un oficio directamente vinculado con el coro. Por otra parte, es indispensable señalar que este nombramiento corrobora que Vicente Olmos también fue instruido por el maestro Pascual Fuentes que había accedido al magisterio de capilla de la Metropolitana de Valencia por oposición con la jubilación de su antecesor, el maestro Pradas, en 1757. Aparte de esta importante circunstancia, el nombramiento de Vicente Olmos Claver como Moso de Capella se produjo con fecha 22 de junio de 1762 mediante Protocolo notarial en función de la relevancia que el cabildo otorgaba a las relaciones con la capilla de música:

\footnotetext{
4 (ACV): Libro de salarios y nombramiento de Capellanes cantores y de músicos de 1605 a 1810, (s.f.r.), documento del año 1754.

5 (ACV): 590. Bolsa de coro. Distribuciones o jornadas de coro desde 1750 a 1755. 5537, (s.f.r.).
} 


\section{El MAESTRO DE CAPILLA VICENTE OLMOS ClAVER Y SU APORTACIÓN A LA} MÚSICA RELIGIOSA ESPAÑOLA DEL SIGLO XVIII

Nominació de Moso de Capella â Vicent Olmos. Ab acte per dit Gargallo en 22. De Juny de 1762. Lo molt Ilustre Capítol nomenà â Vicent Olmos Infantillo per a la Plaza de Moso de Capella, per assens de Manuel Campos â la Plaza de Acolit, ab lo Salari Anuo, y demes emoluments perteneixents â dít empleo .

Poco después, la trayectoria de Vicente Olmos en la Catedral de Valencia encuentra uno de sus puntos álgidos con la aparición de sus primeras composiciones musicales. Concretamente del año 1763 son el Salmo Dixit Dominus de $1^{\circ}$ tono $^{7}$ a 8 voces con acompañamiento de órgano y otro, y, también, el Salmo Beatus Vir de $2^{\circ}$ tono asimismo para doble coro con acompañamiento de órgano y continuo. Ambas composiciones están firmadas por el $M[$ aest $] r \hat{o}$ Olmos por lo que no podemos dejar de pensar, por una parte, que desde muy joven contó con cierto reconocimiento, y, por otra, además, que aún no había tomado órdenes como Presbítero. Aunque ambas obras pertenecen a la etapa de nuestro músico en la Metropolitana de Valencia, actualmente se conservan en el archivo de la Santa Iglesia Catedral de Segorbe donde, como veremos más adelante, el mismo Olmos debió quizás depositarlas.

Vicente Olmos iniciaba con estas composiciones musicales una producción que ya no interrumpió hasta el final de sus días. De hecho, poco después, en 1765, escribió una de las obras seguramente más significativas de su repertorio; Misa â 4. y â 8. con Violines, Oboeses, y Tromp.[a]s. La obra está escrita para doble coro con acompañamiento instrumental de dos violines, dos oboes, dos trompas y continuo. Se conserva desafortunadamente incompleta en el archivo musical de la Catedral de Segorbe, lo que ha impedido su transcripción para nuestros trabajos previos de edición crítica. Con todo, nos gustaría resaltar la importancia de esta obra en el repertorio de Vicente Olmos por el hecho de tratarse de una forma musical compleja generalmente planteada por los compositores en períodos ya maduros de creación. En ese sentido, es indispensable remarcar que Vicente Olmos escribió esta obra siendo aún un joven músico, presumiblemente de no más de veinte años, que estaba en período de formación en la Catedral de Valencia. Sin embargo, no nos ha llegado ninguna otra Misa hasta nuestros días, circunstancia un tanto sorprendente, porque, el análisis de la evolución artística de nuestro músico nos invita a pensar que Olmos debió escribir alguna otra Misa a lo largo de su vida. Finalmente, queremos destacar que en los manuscritos del músico la obra consta firmada por $M$.[osé] $n$ Vicente Olmos, de lo que se deduce que presumiblemente tomó las órdenes como Presbítero entre 1763 y 1765.

Las fuentes bibliográficas consultadas nos dicen que Olmos ocupaba en 1768 el cargo de Acólito en la Catedral de Valencia; “... sabemos que en 1768 hallábase en la Metropolitana de Valencia desempeñando un cargo intitulado Acólito, siendo ya Presbítero..." (Perpiñán, 1897, p. 269). Con este nuevo cargo, Vicente Olmos asumía

\footnotetext{
${ }^{6}$ (ACV): Libro de salarios, Op. cit., (f. 196), documento del año 1762.

7 (ACS): PM 22/1.

8 (ACS): PM 22/6.

9 (ACS): PM 22/12.
} 
nuevas responsabilidades dentro de la capilla de música de la Catedral y culminaba el proceso regular de los niños que se formaban en la institución; se iniciaban como Infants, después pasaban a ser Mosos de Capella y, finalmente, Acolit de la capilla de música de la Catedral Metropolitana de Valencia. Por nuestra parte, no hemos podido encontrar el nombramiento de Acólito de nuestro Vicente Olmos, aunque, sin embargo, hemos conseguido numerosos documentos que reconocen el nuevo cargo ${ }^{10}$. El estudio de todos ellos nos ha permitido comprobar que en la Metropolitana de Valencia a los Acólitos también se les denominaba ocasionalmente Moso de Coro (Marzal, 2019, p. 119 s.) De hecho, en 1771, los Protocolos del Cabildo firmados por el notario de la Catedral Pere Rodrigo prorrogaban el oficio de Moso de Coro de Mosén Vicente Olmos ${ }^{11}$.

También es importante decir que en 1768 accedía al magisterio de capilla de la Metropolitana de Valencia el maestro Francisco Morera. De esta manera, la etapa de Vicente Olmos Claver en la Catedral de Valencia se solapa con el magisterio de tres de los grandes maestros de la música religiosa valenciana del siglo XVIII; José Pradas, Pascual Fuentes y Francisco Morera. La cuestión no es menor, porque, sin duda, Vicente Olmos se nutrió técnica y estilísticamente de estos compositores que, de hecho, ocuparon el magisterio de la Metropolitana durante la mayor parte de la centuria.

De otra parte, resulta indispensable señalar que Vicente Olmos continuaba con su actividad creativa, porque, en ese mismo año de 1768, escribió una nueva composición asimismo relevante en su aportación musical; el villancico para la Profesión de Sor Maria Joachina ${ }^{12}$ Religiosa en el Convento de San Julián. Los manuscritos musicales se encuentran en el archivo de la Catedral de Segorbe, pero, además, podemos cotejar el texto poético en un documento que conserva la Biblioteca Universitaria de Valencia ${ }^{13}$. La composición está escrita para seis voces; dos Tiples solistas más un coro completo di ripieno. Paralelamente, la instrumentación cuenta con dos Violines, dos Clarines, Bajo continuo y Órgano. Los manuscritos de la obra no están completos, no obstante que, su análisis permite comprobar que cuenta con "Aria y Recitado"; estructura de inequívoca procedencia italiana cuyo uso denota que nuestro Olmos Claver no era ajeno a las tendencias más avanzadas de su tiempo. Con todo, es necesario remarcar que se trata del primer villancico compuesto por Vicente Olmos; un género que, como veremos más adelante, cultivó extensamente en su trayectoria de creación musical. Además, también conviene resaltar que este villancico se escribió para la "Solemne Profesión" de una religiosa bija del Theniente Coronel Don Alonso, Sargento Mayor de Esta Plaza, circunstancia que para algunos investigadores permite establecer relaciones de Vicente Olmos con los ámbitos de poder; En qualsevol cas, ja des de l'any 1768 sembla mantenir cordials relacions amb l'estament militar, ... (López y Olmos, 1983, p. 16).

\footnotetext{
10 (ACV): 3335 Protocolos del cabildo $17682^{\text {a }}$, Notario Pere Rodrigo, 9 de mayo, (f. 22 v.). (ACV): 1278 Deliberaciones capitulares, 302, Verbales 9 stbre 1709 a 1775, (s.f.v.), documento de 9 de mayo de 1768. (ACV): Deliberaciones capitulares, Op. cit., (f. 69 r.), documento de 9 de mayo de 1768.

11 (ACV): 3340 Protocolos del cabildo $17711^{\text {a }}$, Notario Pere Rodrigo, 8 de enero, (f. 247).

12 (ACS): PM 22/27

13 (BUV): Varia, 331-2.
} 


\section{Vicente Olmos maestro de la Capilla de música del Palacio Real de ValenCia}

La primera noticia acerca del acceso de Vicente Olmos Claver al magisterio de la capilla de música del Palacio Real de Valencia la encontramos en la documentación de la Catedral Metropolitana de Valencia. El cabildo catedralicio otorgaba a finales de 1768 Permiso y Licencia a nuestro Vicente Olmos para admitir el Magisterio de Capilla del Palacio Real de Valencia:

Permíso dado â Mosen Vícente Olmos Clergue Acolíto de esta S.ta Igt.a para poder admítír el Magísterío de Capílla del Palacio real, bíen que no faltando â la Asistencia de este Choro, en 22. de Dez.e de 1768.- 73 B ${ }^{14}$.

Mestre de Capella del Real, M.n V.t Olmos Acolit de esta S.ta esgt.a. En dit dia donaren Licencia a Vte Olmos Clergue Acolít dela present esglesia pera admitír lo nomenament de Mestre de Capella del Palacio del Real ab la condício que hacha de asistir en esta Esglesia en tot lo que li perteneís per rao dedit empleo de Acolit sens fer may falta ${ }^{15}$.

Un mes más tarde, en enero de 1769, se firma un "Protocolo notarial" que certifica la fundación de una capilla de música de nueva creación en el Palacio Real de Valencia erigida a la advocación de Santa Catalina Mártir. Dicho "Protocolo" consta de ocho documentos firmados ante el notario Juan Antonio Espada entre enero de 1769 y octubre de 1770. Toda esta documentación fue publicada por el investigador Fernando Pingarrón Seco en la revista Cabanilles (Pingarrón, 1983). Su publicación supuso una primicia no solo en aquello que, como veremos a continuación, atañe a Vicente Olmos Claver sino también como contribución al estudio de las capillas musicales valencianas del siglo XVIII.

El segundo documento del citado "Protocolo notarial" contiene el que podríamos reconocer como documento fundacional de esta capilla de música del Palacio Real de Valencia firmado el 23 de enero de 1769. En la primera parte de dicho documento consta como maestro de capilla Mosén Vicente Olmos, clérigo. Además, también aparecen los nombres de los músicos que conformaban la nueva capilla y la función que cada uno de ellos desempeñaba como instrumentista o bien como cantor; seis voces y cinco ministriles. En el mismo documento, más adelante en la parte dedicada a los estatutos fundacionales, aparecen expresiones como obedecer al Maestro, todos a la voz del Maestro, complacer al Maestro o le pareciere al Maestro que certifican el liderazgo de Vicente Olmos Claver en esta recién creada capilla del Palacio Real de Valencia. Asimismo, consta que el Maestro tendría la más alta remuneración:

14 (ACV): Deliberaciones capitulares, Op. cit., (s.f.r.), documento de 22 de diciembre de 1768.

15 (ACV): Deliberaciones capitulares, Op. cit., (f. 73 v.), documento de 22 de diciembre de 1768. 
Otrosí: Que à ninguno de esta Capilla, por habilidad, que sea, se le hagan dos porciones, exepto al Maestro que tiene dos, la una por asistir al acto, y llevar el compas, y la otra por componer, y dàr a los musicos las obras, yà copiadas, teniendo dicha Capilla provision correspondiente de Musica ${ }^{16}$.

Vicente Olmos también recibiría una remuneración económica de tres libras por dàr liccion a los Niños, és decir, a los Ynfantillos, que, debían vestirse para las funciones como estimare por mas conbeniente el Maestro. La nueva capilla del Palacio Real de Valencia nacía con la voluntad de configurarse con una plantilla de dieciocho músicos además de los “infantillos". La admisión de los músicos se realizaría por votada canónica, pero, para elegir al Maestro, los músicos debían tener al menos tres años de antigüedad en la capilla. Finalmente, la lectura de la parte final de este documento confirma, si cabe aún más, la relevancia del maestro Olmos dentro de este colectivo; Que deva preguntar si la fiesta es de Santo, ò, Santa, ò a que Ymagen, para avisar al Maestro, y este pueda arreglar la música... ${ }^{17}$.

Por otra parte, conviene recordar que el acceso a las capillas musicales eclesiásticas se realizaba por oposición con edictos o por designación. Todo parece indicar que Vicente Olmos Claver accedió al magisterio de la capilla de música del Palacio Real por designación. No hay ningún documento que haga referencia a ninguna oposición ni nada semejante. Entonces, la cuestión es por qué razón, cómo, quién o quienes decidieron nombrar maestro a nuestro Vicente Olmos. La respuesta no es sencilla, sin embargo, podemos aportar algunos argumentos que seguramente pueden ayudar a responder algunas de estas preguntas.

En primer lugar, es indispensable recordar la relación de Mosén Vicente Olmos con el estamento militar. Como ya hemos visto, Olmos escribió un villancico para la ceremonia de ingreso de la hija de un Theniente Coronel en la Orden del Gran Padre San Agustin. No obstante, en nuestra opinión podría haber sido determinante la intervención de un personaje muy influyente de la sociedad valenciana de la época; Francisco Xavier de Oloriz. Eclesiástico Beneficiado de la Catedral Metropolitana de Valencia donde ocupaba la titularidad de la Capilla de Santa Lucia, Oloriz estaba agregado a la Capellania mayor del Real. Así, Francisco Xavier de Oloriz era la máxima autoridad eclesiástica del Palacio Real de Valencia, de manera que, debió sin duda intervenir en el nombramiento de Vicente Olmos. Teniendo en cuenta su posición en la Catedral Metropolitana, podría haber pedido informes al mismo maestro de capilla y a su entorno acerca de las capacidades musicales de Vicente Olmos ${ }^{18}$.

\footnotetext{
16 (ACPV): Protocolo no 350, (f. 26 v. a 31), 23 de enero de 1769, notario Juan Antonio Espada. Cfr. (Pingarrón, 1983, p. 13).

17 Ibidem. Cfr. Pingarrón, 1983, p. 14.

18 "El musicòleg Samuel Rubio ha documentat l'existència de recomanacions als processos d'accés a mestre de capella, la qual cosa podria haver sigut decisiva en el cas del nostre Vicent Olmos. En primer lloc, cal tindre en compte que Vicent Olmos es va formar musicalment a la Catedral Metropolitana de València, on va ser deixeble de quasi tots els mestres que la Seu va tindre durant el segle XVIII. D'aquesta manera, el vincle entre la Catedral Metropolitana de València i el Palau Reial a través de la figura de Francisco Xavier d'Oloriz podria haver sigut determinant en l'ascens del nostre Olmos. [El musicólogo Samuel Rubio ha documentado la existencia de recomendaciones en los procesos de acceso a maestro de capilla, un hecho que podría haber
} 
En el Palacio Real de Valencia hubo liturgia cristiana desde su génesis en 1238 cuando el mismo Rey Jaime I instituía una primera capilla erigida a la advocación de San Jaime Apóstol. Se iniciaba así una tradición que iba a mantenerse durante siglos en todos los reinados tanto de la Corona de Aragón como de la de España. Según nos dicen algunos estudios, el Palacio Real de Valencia tuvo durante todo ese largo tiempo distintas capillas con diversas advocaciones que contaron con variadas capellanías y altares (Arciniega y Serra, 2006a y 2006b) (Gómez-Ferrer y Bérchez, 2003). De entre toda esta organización para las numerosas celebraciones destacan las capillas erigidas a Nuestra Señora de los Ángeles, y, sobre todo, en cuanto a nuestro trabajo sobre Vicente Olmos Claver, la capilla erigida a Santa Catalina Mártir.

Como ya hemos visto, la nueva capilla dirigida por Vicente Olmos se fundó en 1769 a la advocación de Santa Catalina Mártir con la finalidad de atender las funciones religiosas del Palacio Real. Sin embargo, esta iniciativa contravenía el "concordato" firmado ante notario apostólico más de veinte años antes, en 1747, por algunas de las principales capillas eclesiásticas de Valencia; las capillas de las parroquias de San Martín, San Juan del Mercado y San Andrés. La información acerca de toda esta cuestión fue publicada por el investigador Jesús Villalmanzo describiendo las disputas que se generaban a cuenta del reparto de las distintas funciones que se celebraban en la ciudad de Valencia ${ }^{19}$.

La documentación del Archivo del Reino de Valencia nos ha permitido comprobar que durante la primera parte del siglo XVIII, tanto desde la administración del Conde de Peñalva entre 1707 a 1717 como posteriormente desde la Superintendencia General a partir de 1717, las celebraciones del Palacio Real de Valencia fueron interpretadas por la capilla de música de la parroquia de San Martín. Nuestra investigación nos permite decir asimismo que a partir de 1759 tomó el relevo la capilla de música de la Seo, es decir, la de la Catedral Metropolitana de Valencia (Marzal, 2019, pp. 152 s.). Con todo, la creación de la nueva capilla dirigida por Vicente Olmos reiniciaba con las "capillas concertadas" un conflicto que la "concordia" de 1747 había cerrado. De hecho, el pleito no tardó en llegar y su resolución exigió la intervención de las más altas autoridades del Estado español.

El Archivo del Reino de Valencia guarda una carta enviada por el Marqués de Grimaldi, Secretario de Estado del gobierno de Carlos III, al Sr. Don Gaspar de Navas, máxima autoridad de todo el territorio valenciano, informando de la reclamación efectuada

sido decisivo en el caso de nuestro Vicente Olmos. En primer lugar, es necesario tener en cuenta que Vicente Olmos se formó musicalmente en la Catedral Metropolitana de Valencia, donde fue discípulo de casi todos los maestros que la Seo tuvo durante el siglo XVIII. De esta manera, el vínculo entre la Catedral Metropolitana de Valencia y el Palacio Real a través de la figura de Francisco Xavier de Oloriz podría haber sido determinante en el ascenso de nuestro Olmos.]” (Marzal, 2019, pp. 133 s.).

19 "Ante tal estado de cosas las tres capillas -la de San Martín, San Juan del Mercado y San Andrés- resuelven unirse y hermanarse. Para ello firmaron una Concordia que recibió el notario apostólico y público de Valencia Carlos Vicente Seguí, el día 6 de octubre de 1747, la cual consta de 32 capítulos, siendo sus principales puntos aquellos que se refieren a la fijación del precio de cada actuación según fuese misa, vísperas, procesiones, etc., y según el número de músicos e instrumentos que interviniesen en las mismas. ... Este período de las capillas musicales parroquiales, desde 1747 a su extinción en el primer tercio del siglo XIX se conoce como el de las Capillas Concertadas, a las que hace continuas alusiones el barón de Alcahalí en su conocida obra" (Villamanzo, 1972, p. 22). 
a la Corona a propósito de la creación de la nueva capilla de música del Palacio Real de Valencia. Gracias a este documento, publicado por historiadores valencianos (López y Olmos, 1983), conocemos todo este proceso que finalmente concluyó con una resolución favorable del Rey Carlos III que legitimaba la capilla de música fundada en el Palacio Real de Valencia. Dicha resolución comportó la firma de nuevos acuerdos en 1776 entre las distintas capillas implicadas en la controversia según hemos podido comprobar documentalmente en el Archivo del Reino de Valencia. Sin embargo, todo parece indicar que Vicente Olmos ya no participó en dichos acuerdos porque en 1772 inició una nueva etapa biográfica como maestro de capilla de la Santa Iglesia Catedral de Segorbe (Marzal, 2019, p. 146).

De este período biográfico en la capilla del Palacio Real nos han llegado asimismo dos salmos polifónicos del año 1770; Beatus vir â $6^{20}$ y Laudate Dominum. â $5^{21}$. Son composiciones de carácter policoral firmadas por Mosén Vicente Olmos. En cuanto al primero, Beatus vir, podemos decir que está escrito efectivamente a seis voces; Soprano y Tenor solistas junto a un segundo coro completo. Paralelamente, la plantilla instrumental cuenta con dos violines, dos trompas, acompañamiento continuo y órgano. Los manuscritos de la composición se conservan completos en el archivo de la Catedral de Segorbe. Así, hemos podido transcribir íntegramente la obra para nuestra edición crítica (Marzal, 2013, pp. 978-1037). Por su parte, el citado Laudate Dominum está escrito para Soprano solista con un segundo coro di ripieno. La instrumentación es un poco más amplia con dos violines, dos oboes, dos clarines, acompañamiento continuo y órgano. Pertenece asimismo al archivo de la Catedral de Segorbe y también hemos podido transcribirlo íntegramente para nuestra edición crítica (Marzal, 2013, pp. 1069-1106).

No obstante, nuestro estudio nos ha permitido verificar que en el "Real" de Valencia había una intensa actividad litúrgica con distintas celebraciones tradicionales en el calendario (Marzal, 2019, pp. 151-157). De acuerdo con esto, Olmos debió sin duda escribir muchas más obras durante este período. De hecho, entre los manuscritos de nuestro músico existen varias composiciones sin fecha que quizás podrían pertenecer a esta misma etapa biográfica. Además, el maestro Olmos escribió en 1772 otras cuatro composiciones que, sin embargo, hemos juzgado más atribuibles al período que comentaremos seguidamente del maestro en la Catedral de Segorbe.

Resumiendo, podemos decir que la etapa de Vicente Olmos Claver como maestro de capilla del Palacio Real abarca aproximadamente desde finales de 1768 hasta principios de 1772. Así, resulta muy relevante para nuestra investigación certificar documentalmente que nuestro Vicente Olmos Claver compaginó el magisterio de capilla en el Palacio Real con su actividad como Acólito en la capilla de música de la Catedral Metropolitana de Valencia. Cabe recordar que, como hemos visto al principio de este apartado, a Vicente Olmos se le permitió admitír la dirección de la capilla del "Real" ab la condício que hacha de asistir en esta Esglesia en tot lo que li perteneís per rao dedit empleo de Acolit sens fer may falta ${ }^{22}$.

\footnotetext{
20 (ACS): PM 22/5.

21 (ACS): PM 22/7.

${ }^{22}$ Cfr. p. 7.
} 


\section{El magisterio de Capilla de Vicente Olmos en la Santa Iglesia Catedral DE SEGORBE}

La fuente bibliográfica más temprana que hemos cotejado en nuestra investigación nos decía que Vicente Olmos Claver accedía por oposición al magisterio de capilla de la Catedral de Segorbe a finales del mes de febrero de 1772; "Por profesión religiosa del Maestro Vives, vacante el Magisterio de Capilla de Segorbe, fue agraciado, mediante oposición, el Presbítero Mosén Vicente Olmos en 28 de Febrero de 1772, los ejercicios de oposición se celebraron en 19 del mismo mes” (Perpiñán, 1897, p. 268 s.).

Desafortunadamente, la Catedral de Segorbe no conserva la documentación capitular de 1772, circunstancia que nos ha privado de conocer con detalle todo el proceso de oposición y, en definitiva, la transición desde el magisterio de Francisco Vives, inmediato antecesor de Olmos en el cargo, al nombramiento como maestro de Vicente Olmos. No obstante, el Archivo Diocesano de Valencia conserva un Libro de Memorias de la Catedral de Segorbe que contiene una Memoria de lo sucedido en la oposición del Magisterio de Capilla hecha en la Sta. Igla. En el presente año de $1762^{23}$. Como su título indica, este documento describe con detalle las oposiciones celebradas diez años antes para cubrir el magisterio de la Catedral de Segorbe siendo nombrado entonces el citado Francisco Vives. Cabe pensar, por tanto, que las oposiciones de Vicente Olmos no debieron diferir sustancialmente de éstas. Además de resaltar la importancia del documento en lo que atañe a nuestro músico, merece la pena destacar su relevancia como contribución al estudio de las capillas musicales eclesiásticas del siglo XVIII. Con todo, nuestros trabajos previos describen extensamente el contenido de toda esta documentación (Marzal, 2013, p. 291 ss.; Marzal, 2019, p. 167 ss.).

De la oposición realizada por Vicente Olmos Claver al magisterio de capilla de la Catedral de Segorbe solo se ha conservado parcialmente uno de los ejercicios; Villancico que hizo para la oposición... ${ }^{24}$. Después de más de doscientos años desde su composición, lamentablemente solo nos ha llegado una única parte del Tiple del $1^{\circ}$ Coro con fecha, efectivamente, de febrero de 1772. Aun así, el documento nos ha permitido comprobar que la estructura formal de esta composición musical consta de Introducción-Estribillo-Recitado y Aria da capo, lo que corrobora una vez más que Vicente Olmos conocía las formas italianas instauradas en el panorama musical de la época. Olmos debió superar distintas pruebas en esta misma oposición, pero, según nos dice el canónigo de Salamanca José Artero, la composición del villancico era la prueba transcendental en este tipo de oposiciones ${ }^{25}$.

\footnotetext{
23 (ADV): 525/4. Libro de memorias, y antiguedades, y particulares deliberaciones de la Cathedral Yglesia de la presente Ciudad de Segorbe, hecho por su muy Ille. Cabildo, y empieza en el presente año 1754. (f. 18 v. a 21 r.).

24 (ACS): PM 22/13.

25 "Pero el ejercicio que se consideraba transcendental..., era un Villancico, según lo que en España se estilaba por aquellos tiempos. Constaba de una Introducción a 4 voces, un estribillo a 8 y orquesta, un recitado con acompañamiento de bajo cifrado u orquesta, como los de las óperas de Monteverdi o Gluck o las Pasiones de Bach, y una Aria para solo..." (Artero, 1947, p. 195).
} 
Aunque la Catedral de Segorbe, como hemos dicho, no conserva las actas capitulares de 1772, afortunadamente, ha conservado un Libro de actas capitulares que abarca desde 1778 hasta $1788^{26}$ donde hemos podido encontrar numerosas noticias inéditas sobre Vicente Olmos Claver. De entre todas ellas, podemos citar que en enero de 1779 consta la intervención de nuestro músico como "Director" en las oposiciones celebradas para cubrir dos succentorías vacantes ${ }^{27}$. Además, ese mismo mes, Vicente Olmos debió dirigir como maestro de la capilla de música de la Catedral de Segorbe el Te Deum Laudamus que se cantó a su Divina Magestad el Rey celebrando “... el feliz, y deseado parto de la S.ra Princesa nuestra S.ra:..."28. Asimismo en 1779, nuestro músico presentaba al Cabildo, en virtud de haver quedado despedido en el cavildo antecedente el infante Andrés Silvestre, cuatro "infantillos" para cubrir dicha vacante ${ }^{29}$. Sin embargo, el análisis de la citada documentación capitular refleja que en estas mismas fechas Vicente Olmos ya había empezado a distanciarse de la Catedral de Segorbe.

En mayo de 1779 el Cabildo catedralicio de Segorbe mostraba su preocupación por el hecho de que el maestro de capilla, que se encontraba ausente de la localidad, “...descuidava algún tanto de la enseñanza de composición a los infantillos,...” ${ }^{30}$. Poco después, Vicente Olmos pedía licencia para ausentarse ${ }^{31}$ y en noviembre de 1779, el Cabildo reconocía que “... mosén Vicente Olmos maestro de Capilla avía tomado el ábito de Religioso Gerónimo en el monasterio de la Murta..."32 de Alzira. No obstante, es el acta del día 8 de noviembre de 1780 la que declara vacante el magisterio de capilla de la Santa Iglesia Catedral de Segorbe registrando asimismo que Vicente Olmos había enviado una carta al Cabildo en la que “... este dava cuentas de haver el mismo en el día 1 de los corrientes hecho solemne profesión de monge Religioso Gerónimo en el monasterio de la Murta,..."33. De esta manera, Vicente Olmos abandonaba el magisterio de capilla de la Catedral de Segorbe para iniciar una nueva etapa biográfica como monje Jerónimo de la que hablaremos a continuación. La vacante de Olmos fue cubierta por Mosén Joaquín López.

Vicente Olmos Claver fue maestro de la capilla de música de la Catedral de Segorbe desde 1772 hasta 1780. Teniendo en cuenta la cronología de los manuscritos que han llegado hasta nuestros días, este período de su biografía es musicalmente el más prolífico de toda su trayectoria. Durante sus cerca de nueve años de magisterio en Segorbe, Olmos escribió treinta y siete composiciones de entre las cuales destacan numéricamente los villancicos litúrgicos. El archivo de la Catedral de Segorbe conserva toda la producción de este período cronológico; un Salmo, dos Lamentaciones, un "Verso", un "Quatro", las "Completas", un Aria a dúo, y treinta y tres villancicos. Además de reiterar la extraordinaria creatividad que encontramos en la composición de villancicos litúrgicos, nos gustaría

\footnotetext{
26 (ACS): Libro de actas capitulares, 1778-1788.

27 (ACS): Libro de actas capitulares, Op. cit., (f. 13 v.), (14-1-1779).

28 (ACS): Libro de actas capitulares, Op. cit., (f. 15 r.), (27-1-1779).

${ }^{29}$ (ACS): Libro de actas capitulares, Op. cit., (f. 34 v.), (23-8-1779).

30 (ACS): Libro de actas capitulares, Op. cit., (f. 24 v.), (8-5-1779).

31 (ACS): Libro de actas capitulares, Op. cit., (f. 39 v.), (16-10-1779).

32 (ACS): Libro de actas capitulares, Op. cit., (f. 40 v.), (3-11-1780).

33 (ACS): Libro de actas capitulares, Op. cit., (f. 89 v.), (8-11-1780). 
destacar la singularidad del Quatro ${ }^{34}$; composición de 1774 escrita para un cuarteto vocal de tres Tiples y un Tenor con acompañamiento cifrado. La obra fue escrita "... para dar las Pasquas... â los Seño.[res]s obispo, y Canonigos. ...”.

\section{Vicente Olmos en el monasterio de Nuestra Señora de la Murta de} AlZIRA

Nuestro estudio sobre Vicente Olmos Claver nos lleva a pensar que el músico debió conocer una Casa Jerónima emplazada en la ciudad de Segorbe; Nuestra Señora de la Esperanza. Hipotéticamente, debió establecer allí sus primeros contactos con la Orden de San Jerónimo decidiendo en determinado momento renunciar al magisterio musical de la Catedral de Segorbe para tomar los hábitos como monje Jerónimo en el monasterio de Nuestra Señora de la Murta de Alzira. El estudio de las actas capitulares de dicho cenobio, que conserva la sección "Clero" del Archivo del Reino de Valencia, nos ha facilitado información que ha permitido ampliar notoriamente la biografía de Olmos Claver ${ }^{35}$. No obstante, es indispensable señalar que hemos trabajado con la transcripción de dicha documentación realizada por el historiador Aureliano Lairón Pla (Lairón, 2001b y 2001c).

El acta capitular del monasterio de la Murta que registra el inicio del proceso de ingreso en la Orden Jerónima de Vicente Olmos Claver es del día 27 de octubre de 1779. Dicho documento capitular recoge que Olmos Claver llegó al monasterio con la condición de presbitero, que había sido maestro de capilla de la Catedral a la ciudad de Segorbe, y que era natural de la villa de Catarroxa. Asimismo, el documento certifica suficiencia de lectura, gramática, voz y vista, a la vez que reconoce buenos informes de su vida, costumbres y limpieza de sangre. Así, la primera recepción comportaba la imposición del hábito siempre que el pretendiente fuera aceptado por toda la comunidad del monasterio. Después, habría otras tres recepciones más antes de continuar con el proceso de ingreso en la Orden Jerónima ${ }^{36}$. Las actas capitulares de los días 2 de marzo de $1780^{37}$, 25 de julio de $1780^{38}$ y 8 de septiembre de $1780^{39}$ certifican que Vicente Olmos Claver fue debidamente acogido por la comunidad de los Jerónimos de la Murta de Alzira.

Después de estas cuatro recepciones iniciales, el novicio consolidaba la integración en la Orden de los Jerónimos mediante la ceremonia de "Profesión". Dicho acto suponía asumir un compromiso absoluto con la religión y con la Iglesia mediante una promesa de carácter moral y espiritual. Previamente a la ceremonia de "Profesión", la Orden de los

\footnotetext{
34 (ACS): PM 22/16.

35 (ARV): Libro de actos capitulares del monasterio de Nuestra Señora de la Murta, 1661-1782. (ARV): Libro de actos capitulares del monasterio de Nuestra Señora de la Murta, 1782-1835.

36 "Durante el noviciado y antes de la profesión al aspirante a aquella se le debía recibir -venía a significar su aprobación- por cuatro veces: la primera para darle el hábito, la segunda a los cuatro meses, la tercera a los ocho y la cuarta y última a los diez. Para las recepciones debían ser convocados todos los vocales al capítulo. Cada una de las recepciones debía contar con la aprobación del prior y capítulo, de manera que si uno de los dos no consentía aquellas no eran válidas” (Lairón, 2001a, p. 224).

37 (ARV): Libro de actos capitulares, 1661-1782, Op. cit. (2-3-1780). Cfr. Lairón, 2001.

38 (ARV): Libro de actos capitulares, 1661-1782, Op. cit. (25-7-1780). Cfr. Lairón, 2001.

39 (ARV): Libro de actos capitulares, 1661-1782, Op. cit. (8-9-1780). Cfr. Lairón, 2001.
} 
Jerónimos recababa más información sobre el novicio, que, necesariamente debía cumplir con todas las exigencias normativas, entre las cuales, por ejemplo, haber redactado el testamento o superar expediente de limpieza de sangre. Superados todos los requisitos, el aspirante a monje debía solicitar la "Profesión", que, preceptivamente, tenía que ser aprobada por el capítulo y, también, por el Prior del monasterio antes de que éste fijara el día de la ceremonia. Seguidamente, el aspirante redactaba su Carta de Profesión ${ }^{40}$ para posteriormente leerla ante toda la comunidad en la ceremonia de "Profesión"; el acto más importante de todo el noviciado ${ }^{41}$.

Nuestra investigación nos permite decir que el Libro de censales del monasterio de la Murta de Alzira registra la "Profesión" de nuestro compositor efectivamente en noviembre de $1780^{42}$. Siguiendo una costumbre monástica, nuestro Vicente Olmos aprovechó el acto solemne de "Profesión" para mudar su nombre por Fray Vicente de Nuestra Señora de los Desamparados Olmos. A partir de este momento, salvo en muy contadas excepciones, nuestro músico aparecerá con su nombre monástico en toda la documentación biográfica y también en todas sus composiciones musicales ${ }^{43}$.

Pero, además, hemos conseguido en nuestro trabajo uno de los documentos más sobresalientes de toda la biografía de Olmos Claver; la Carta de Profesión de nuestro Fray Vicente de Nuestra Señora de los Desamparados Olmos. Este documento consta en el Libro de Profesiones del monasterio de Nuestra Señora de la Murta ${ }^{44}$ que está guardado en la biblioteca del Ateneo Mercantil de Valencia. Además de señalar que se trata de un documento extraordinario, donde, por ejemplo, nuestro Fray Vicente se declara Chrístíano víejo por los quatro costados, merece la pena destacar que no había constancia ninguna de su existencia y que finalmente ha visto la luz después de más de doscientos treinta años de historia. Está escrito y rubricado de puño y letra por el mismo Fray Vicente Olmos y dada su excepcionalidad lo transcribimos íntegramente a continuación adjuntándolo además como ilustración;

\footnotetext{
40 "Las cartas de profesión son documentos que han de redactar los profesos y profesas de órdenes monásticas y también mendicantes, mediante las que se comprometen a adoptar una forma de vida de acuerdo a lo establecido..." (Alvarez, 2000, p. 493).

41 "Se trata del acto de compromiso del novicio. Supone la consagración del monje a Dios y su afirmación con la Orden que, a través de una de sus comunidades monásticas, le ha acogido en su seno durante un año. La profesión significa el abrazo al estado religioso, al modo permanente de vida común. Para ello, tal y como se puede comprobar a través de las Cartas de Profesión, el novicio prometía -a Dios, a la Virgen, a San Jerónimo y al prior y sus sucesores en el monasterio que iba a profesar- vivir bajo la obediencia, pobreza y castidad, siguiendo la Regla de la Orden” (Lairón, 2001a, p. 225).

42 (ARV): Sección Clero, Libro $\mathrm{n}^{\circ}$ 4163. Libro de censales, rentas, posesiones y emolumentos que poseía el Monasterio de la Murta. (f. 260 r. a 261 v.)

43 "Si bien no se llevaba a cabo con demasiada frecuencia hemos de señalar que la solemnidad se la profesión se aprovechaba por los novicios para mudar el nombre, de forma que adoptaban otro - de normal se cambiaba el nombre de pila cuando no añadían al patronímico el de un santo o santa o la advocación de la Virgen a la que tenían devoción, cuando no cambiaban nombre y apellido- con el que querían ser llamados a partir de ese momento. En ese sentido, gracias a la documentación de que disponemos, hemos podido constatar el cambio, al menos, en una veintena de monjes" (Lairón, 2001a, p. 228).

44 (BAMV): Libro de Profesiones.
} 


\section{EL MAESTRO DE CAPILLA VICENTE OLMOS ClAVER Y SU APORTACIÓN A LA} MÚSICA RELIGIOSA ESPAÑOLA DEL SIGLO XVIII

Yo Fr. Vicente de Ntrâ Señora de los Desâmparados, Sacerdote, y Mtrô de Capilla, que fui de la Cathedral Yglesia de Segorbe, hago profesíon, y prometo obediencía â Díos, y â Santa Maria, y al Bíenaventurado N. P. S. Geronimo, y â Vos Fr. Thomàs de Santa Maria, Prior de este Monasterio de Ntrâ Señora dela Murta de Valencía, orden de N. P. S. Geronimo, y â vuestros successores, y de vivír sin propío, y en castidad hasta la muerte, segun la Regla de Sn Agustín Obíspo; y digo, que soy Chrístíano víejo por los quatro costados; y siempre q.e se hallàre lo contrarío, como es tener alguna raza de Judío, ô Moro, ô otro qualquier impedimento contra las Bullas Apostolicas concedidas â la Orden de N. P. S. Geronimo, quíero ser expelido dela Orden quítandome el Habíto de ella; y la profesíon, q.e hago no me valga, ni para esto tenga alguna fuerza: En testimonío delo qual, escrivo esta Carta, y la firmo de mi nombre, fecha en 1 de Noviembre, del año de 1780.

Fr. Vicente de Ntrâ Señora delos Desamparados [Rubricada] ${ }^{45}$.

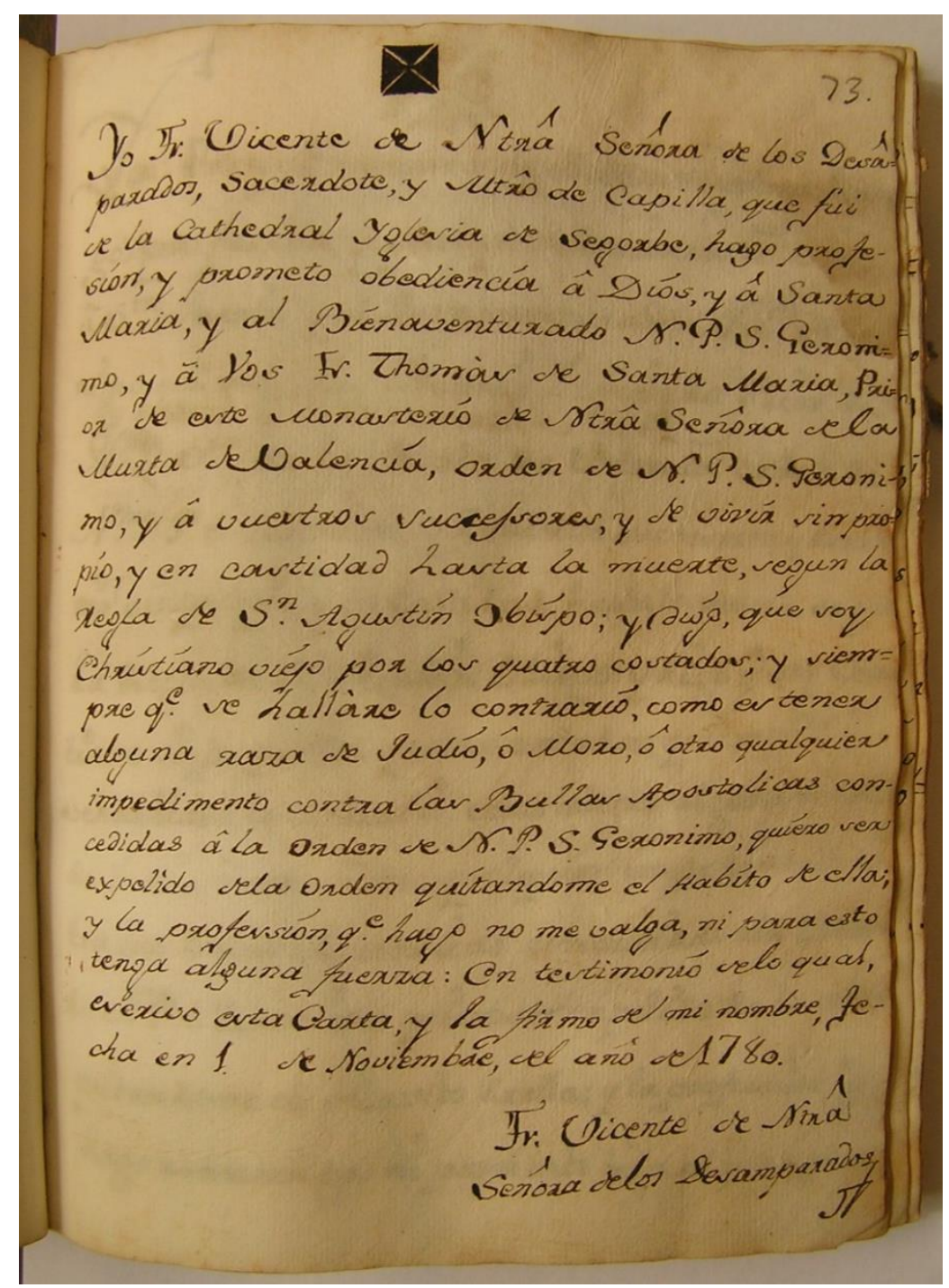

Fig. 1. Carta de Profesión de Vicente Olmos Claver. (BAMV): Libro de profesiones, (f. 73 r.).

45 (BAMV): Libro de Profesiones, (f. 73 r.). 
El análisis de las actas capitulares del monasterio de la Murta también nos ha permitido comprobar que dicha documentación contenía numerosas noticias inéditas sobre nuestro músico. Además, muchas de esas actas capitulares están firmadas por el mismo Fray Vicente de los Desamparados Olmos como responsable de distintos cargos de gobierno del monasterio. A propósito de esta cuestión, debemos señalar que en la Orden de los Jerónimos el noviciado duraba siete años durante los cuales el novicio no podía asumir ninguna responsabilidad en la gestión directiva del monasterio. Con todo, hemos contabilizado más de un centenar de actas capitulares firmadas por Fray Vicente a partir de octubre de 1786, justo siete años después de haber tomado el hábito en la primera recepción. Firmó como Secretario, Cedulero, Secretario interino, Secretario y archivero, Arquero, Arquero primero, Arquero mayor, Arquero y archivero, Archivero, o Archivero mayor ${ }^{46}$.

Las comunidades jerónimas estaban configuradas con monjes de distinta condición; sacerdotes, coristas, legos y donados. El estrato superior lo ocupaban los sacerdotes que se encargaban no solo de toda la liturgia sino que, también, del gobierno del monasterio de manera que eran los únicos que podían ocupar los cargos de gobierno de la comunidad. Así, la condición de sacerdote de Fray Vicente Olmos implica que estaba entre los monjes mejor formados del monasterio, circunstancia que además explica que Olmos participara en la gestión de nueve priores distintos. Además de las actas capitulares, el monasterio de la Murta generó asimismo distintos libros que registran todo el funcionamiento y o administración del cenobio. Así, hemos podido comprobar la existencia de numerosas noticias sobre Fray Vicente de los Desamparados en los siguientes libros ${ }^{47}$ : Libro de las cobranzas $^{48}$, Libro de gastos $^{49}$, Libro de comunidades ${ }^{50}$, Libro de cartas-quenta, ${ }^{51}$ i Libro de rótulos ${ }^{52}$.

La invasión napoleónica provocó la exclaustración de los monjes de la Murta en 1812 de manera que hasta 1814 no se reinició la actividad monástica. Según nos dice el investigador José Manuel Rodrigo Valero, el gobierno afrancesado de José I creó las Delegaciones de Bienes Nacionales para proceder al embargo de los bienes del clero ${ }^{53}$. Una

\footnotetext{
46 Vid. (Marzal, 2019, pp. 212 s.).

47 Vid. (Marzal, 2019, pp. 214 ss.).

48 (ARV): Sección Clero. Libro $n^{\circ} 314$. Libro de las cobranzas de las rentas de Valencia y gastos de su sindico procurador desde 1777 en adelante. La Murta.

49 (ARV): Sección Clero, Libro no 1003. Libro de gastos del monasterio de $N^{a} S^{a}$ de la Murta, año 1785.

50 (ARV): Sección Clero, Libro de comunidades y particulares que responden pensiones de censos y debitorios por la administración de D. Diego Vich y títulos de los que responden en la Marina del monasterio de $N^{a}$ Sra de la Murta de Alzira (1777-1827), libro núm. 962.

51 (ARV): Sección Clero. Libro $n^{\circ}$ 2163. Libro de cartas quenta generales y particulares que empieza en 1 de octubre de 1782.

52 (ARV). Sección Clero. Libro no 960. Libro de rótulos de los capitulos generales celebrados en el real monasterio de San Bartolomé de Lupiana y de cartas comunes y copias de reales despachos del monasterio de la Murta, (años 1733-1797).

53 "La llegada del mariscal Suchet a Valencia en 1812 permitió el inicio en el País Valenciano de la expropiación de los bienes del clero regular. Para su ejecución se tuvo en cuenta un compendio de leyes dictadas por José I y sus ministros entre los años 1809 y 1813" (Rodrigo, 1990, p. 71). "La Administración de Bienes Nacionales, creada en Valencia, procedió a la incautación de todos los bienes muebles e inmuebles de los conventos existentes en la capital valenciana. La circunstancia de que algunas comunidades religiosas tuvieran conventos y propiedades en otros lugares del territorio valenciano, obligará a crear Delegaciones de Bienes Nacionales" (Rodrigo, 1990, p. 73).
} 


\section{EL MAESTRO DE CAPILLA VICENTE OLMOS CLAVER Y SU APORTACIÓN A LA} MÚSICA RELIGIOSA ESPAÑOLA DEL SIGLO XVIII

de estas Delegaciones se estableció en Alzira ${ }^{54}$ iniciando la incautación de los bienes de la Murta mediante un Oficio del día 10 de enero de 1812. Dicho Oficio registra que en la fecha citada solo quedaban cinco monjes en el monasterio, entre ellos, Fray Vicente de los Desamparados que fue testigo de l'adnotación o Inventario del embargo. La incautación fue llevada a cabo, a instancias del Caballero Gobernador de Alzira Don Pedro Palau, por el Comisionado Señor D.n Ignacio de Yangues que estuvo auxiliado por un Alguacil, un Cabo y cuatro soldados $^{55}$. Sin embargo, los Jerónimos de la Murta se habían anticipado al acto de requisición de los bienes y habían trasladado previamente la mayor parte de los Libros, y Documentos justificativos de los bienes que posebia el Monasterio... a la Villa de Xabea, y poder de D.n Juan Bautista Guap ${ }^{6}$. Por su parte, Fray Vicente de los Desamparados ejercía en el momento de la incautación el cargo de Archivero de la comunidad, razón por la cual fue seguramente quien debió informar al Comisionado de la citada circunstancia en el momento del embargo.

Al margen de que los acontecimientos demuestran la relevancia de Vicente Olmos en todo el proceso y, en definitiva, que fue uno de los monjes destacados dentro de la comunidad, es interesante señalar que el documento de confiscación se firma finalmente el 9 de abril de $1812^{57}$. La documentación de la Murta registra asimismo que efectivamente entre 1812 y 1814 no hubo actividad en el monasterio; ... con motivo de la invasión de los franceses se disolvió la Comunidad, y todos los Monges se marcharon a sus casas, ... ${ }^{58}$. De esta manera, Fray Vicente de Nuestra Señora de los Desamparados Olmos regresó a su localidad natal de Catarroja donde falleció, en una fecha indeterminada lógicamente posterior al citado 9 de abril, ese mismo año de 1812 según consta en el Libro de Misas del monasterio: "Murió en Catarroxa el año 1812. Estan celebrados los Nocturnos y Misas correspondientes a sus adelantadas, y de esos dias: óbito, séptimo, trigésimo y Aniversario ${ }^{\text {'59. }}$.

Fray Vicente Olmos estuvo en el monasterio de la Murta de Alzira más de treinta años. De hecho, esta etapa en la Murta es con mucho la más larga de las distintas que hemos podido esbozar en su biografía. Sin embargo, solo han llegado hasta nuestros días seis composiciones musicales de este largo período; Dixit Dominus a $6^{60}$, Miserere â 4 . Llano, $^{61}$, Lamentación â Solo. $2^{a}$ del Miercoles ${ }^{62}$, Magnificat a 6. Con Violines, y Trompas ${ }^{63}$, Lamentación â Duo para el Miercoles $2^{0.64}$, y Lamentación â tres. Tercera del Jueves. ${ }^{65}$. No obstante, el análisis de su trayectoria de creación nos permite decir que Olmos debió escribir muchas más. En primer lugar, merece la pena recordar su precocidad creativa con sus primeras

\footnotetext{
54 "Delegaciones de Bienes Nacionales: Segorbe, Murviedro (Sagunto), Liria, Alcira, Dénia, San Felipe (Játiva), Montesa" (Rodrigo, 1990, p. 73).

55 (ARV): Inventario de los bienes pertenecientes al monasterio suprimido titulado de la Murta. Año 1812, (f. 2 r. y v.).

56 (ARV): Inventario, Op. cit., (f. 14 r.).

57 Ibid.

58 (ARV): Libro de cartas quenta, Op. cit., (f. 248 v.).

59 (ARV): Sección Clero, Libro de Misas celebradas por su Capellanía, libro núm. 2828, (s.f.r.).

${ }^{60}$ (ACS): PM 22/3. Vid. Marzal, 2019, pp. 361 ss.

${ }^{61}$ (ACV): PM 152/8. Vid. Marzal, 2019, pp. 293 ss.

62 (ACV): 152/9. Vid. Marzal, 2019, pp. 304 ss.

63 (ACS): PM 22/8. Vid. Marzal, 2019, pp. 449 ss.

${ }^{64}$ (ACV): PM 152/10. Vid. Marzal, 2019, pp. 313 ss.

65 (ACV): PM 128/3. Vid. Marzal, 2019, pp. 341 ss.
} 
obras escritas cuando aún era muy joven; seguramente, no llegaba a los veinte años de $\operatorname{edad}^{66}$. En segundo lugar, conviene tener en cuenta la extraordinaria capacidad de creación mostrada en Segorbe, período inmediatamente anterior a la Murta de Alzira, de donde nos han llegado decenas de composiciones. Finalmente, la actividad litúrgica del monasterio debió hacer necesariamente indispensable la composición musical para las distintas celebraciones. Sin duda alguna, Fray Vicente Olmos debió mostrar regularmente sus destrezas como maestro de capilla escribiendo música para la liturgia Jerónima de la Murta. Más allá de toda esta argumentación, nos gustaría señalar que el ingreso en los Jerónimos de la Murta comportó un cambio radical en la composición musical de Fray Vicente Olmos. Mientras que en Segorbe escribió sobre todo villancicos litúrgicos, en la Murta de Alzira solo compuso, lógicamente, obras para la más estricta observancia litúrgica; Salmos, Lamentaciones y Magnificat.

\section{Las composiciones musicales del maestro Olmos Claver. Archivos, TÉCNICA Y ESTILO}

Los manuscritos de las composiciones musicales de Vicente Olmos Claver se encuentran en los archivos musicales de las Catedrales de Valencia y de Segorbe. La Catedral Metropolitana de Valencia conserva cinco composiciones litúrgicas; un Salmo y cuatro Lamentaciones. Por otra parte, el archivo de la Santa Iglesia Catedral de Segorbe conserva cuarenta y ocho composiciones musicales; seis Salmos, dos Lamentaciones, un Verso, una Misa, un Canto evangélico del "Magnificat", una Oración de "Completas", treinta y tres villancicos litúrgicos, un "Quatro", los "Misterios" y un Aria â Duo compuesta para la festividad de la Santísima Trinidad. Todo ello, conforma a día de hoy una extensa producción de cincuenta y tres composiciones musicales manuscritas de Vicente Olmos Claver.

Ambos archivos fueron ordenados y catalogados por el musicólogo José Climent que editó posteriormente los resultados de sus trabajos; el catálogo de la Catedral Metropolitana de Valencia publicado inicialmente en 1979 (Climent, 1979), revisado y reeditado en 2011 (Climent, 2011), y el de la Santa Iglesia Catedral de Segorbe en 1984 (Climent, 1984). El trabajo de Climent dejó las cinco composiciones citadas del archivo de la Catedral de Valencia numeradas consecutivamente, desde el número ocho al once, en la signatura número 152 excepto una de las Lamentaciones que encontraremos en la signatura 128/3 (Climent, 2011, p. 327).

Sin embargo, las cuarenta y ocho composiciones del archivo de la Catedral de Segorbe quedaron ordenadas en treinta y una signaturas porque buena parte de los villancicos litúrgicos están agrupados en series de cuatro en función de su uso litúrgico. No obstante, en la catalogación constan las composiciones asimismo numeradas en la signatura 22, del número uno al treinta, más los "Misterios" en la signatura 29/18. Además, a estas signaturas hay que añadir la número 98/23, que corresponde al Aria $\hat{a}$ Duo, encontrada a raíz de nuestra investigación en el archivo de la Catedral de Segorbe. Se trata de una de las

${ }^{66}$ Cfr. p. 5 s. 


\section{EL MAESTRO DE CAPILLA VICENTE OLMOS CLAVER Y SU APORTACIÓN A LA} MÚSICA RELIGIOSA ESPAÑOLA DEL SIGLO XVIII

novedades inéditas aportadas en nuestro trabajo de Tesis Doctoral (Marzal, 2013). No consta en el ya citado catálogo musical de la Catedral de Segorbe publicado por José Climent (1984).

Conviene tener en cuenta que los archivos de ambas Catedrales han tenido que superar muchísimas circunstancias adversas en su dilatada historia. Sin duda, es ésta una de las principales razones por la que tanto Segorbe como Valencia contienen manuscritos musicales de distinta procedencia que pertenecen a distintas etapas creativas de la biografía del músico. Así, por ejemplo, constan composiciones firmadas por nuestro músico con el nombre natural eclesiástico Mosén Vicente Olmos, pero, también composiciones rubricadas con el nombre monástico Fray Vicente de los Desamparados que, obviamente, pertenecen al período como monje Jerónimo en la Murta de Alzira. Asimismo, conviene señalar que el archivo de la Catedral de Segorbe contiene varias composiciones sin fecha y también algunas otras sin autógrafo del maestro.

Nuestro trabajo de Tesis Doctoral contiene una edición crítica con todas las composiciones de Vicente Olmos Claver que técnicamente permitían su transcripción (Marzal, 2013, pp. 882 a 1511). Dicho trabajo recopila veintidós composiciones del maestro acompañadas de notas críticas y de los respectivos textos poéticos conservadas en diecinueve signaturas de $\operatorname{archivo}^{67}$. No ha sido posible transcribir para nuestra edición crítica algunas de las composiciones del archivo de la Catedral de Segorbe porque con el paso del tiempo han quedado incompletas o muy deterioradas (Marzal, 2013, pp. 628 ss.). Aun así, el trabajo citado contiene diecisiete composiciones del archivo de dicha Catedral guardadas en catorce signaturas ${ }^{68}$. Asimismo, nuestra edición crítica recoge las cinco composiciones musicales del maestro Olmos que contiene el archivo de la Catedral Metropolitana de Valencia porque, afortunadamente, ha conservado los materiales musicales completos ${ }^{69}$. Recientemente, hemos publicado un extracto de nuestra edición crítica que recoge, efectivamente, la totalidad de las composiciones del maestro Olmos conservadas en la Metropolitana de Valencia (Marzal, 2019, pp. 514 a 584).

El trabajo de transcripción y revisión en edición crítica de las obras de Vicente Olmos es sin duda el mayor logro de nuestra investigación. Principalmente porque se trata de composiciones inéditas, pero, además, quizás sobre todo, porque facilita el acceso de buena parte de la música de Vicente Olmos al mundo de la investigación musical y permite después de siglos de silencio la interpretación y la grabación de algunas de sus obras. Con todo, la edición crítica ha permitido profundizar en el análisis de su producción creativa, que, contenido en nuestras publicaciones (Marzal 2013 y 2019), resumimos en este artículo.

\footnotetext{
67 (ACS): PM 22/1, PM 22/2, PM 22/3, PM 22/5, PM 22/6, PM 22/7, PM 22/10, PM 22/11, PM 29/18, PM 22/18, PM 22/19, PM 22/25, PM 22/28, PM 22/16. (ACV): PM 152/8, PM 152/9, PM 152/10, PM 152/11, PM 128/3.

68 (ACS): PM 22/1, PM 22/2, PM 22/3, PM 22/5, PM 22/6, PM 22/7, PM 22/10, PM 22/11, PM 29/18, PM 22/18, PM 22/19, PM 22/25, PM 22/28, PM 22/16.

${ }_{69}$ (ACV): PM 152/8, PM 152/9, PM 152/10, PM 152/11, PM 128/3.
} 
En términos generales, la obra de Vicente Olmos Claver puede dividirse en dos partes genéricas diferenciadas. La primera de ellas estaría conformada exclusivamente por música escrita para la más estricta observancia cultual que hemos clasificado, sencillamente, como "música litúrgica". Su principal característica es quizás la musicalización de textos poéticos en Latín. En este grupo encontraremos los Salmos, las Lamentaciones, el Verso, la Misa, el Magnificat y las Completas. En otro grupo diferenciado podemos clasificar aquellas composiciones musicales escritas, asimismo para funciones litúrgicas, no obstante que, menos rigurosas. Además de permitir sonoridades un tanto alejadas de las prácticas más tradicionales elaboradas con técnicas generalmente más avanzadas, estas obras musicalizan textos en lengua vernácula; en el caso de Vicente Olmos, salvo algunas excepciones muy puntuales, siempre en lengua castellana. En este marco genérico que clasificamos como "música paralitúrgica" constan: un "Quatro", los "Misterios", el Aria â Duo, y, sobre todo, los treinta y tres villancicos litúrgicos.

Con todo, una de las principales características de la obra de Vicente Olmos es la policoralidad. De sus diecisiete composiciones litúrgicas, trece son policorales con obras escritas para cinco, seis u ocho voces. No obstante, en las Lamentaciones se expresa generalmente con voces solistas remitiéndonos a la denominada "Lamentación monódica de carácter virtuosístico" que, de hecho, alcanzó su esplendor en el siglo XVIII ${ }^{70}$. Concretamente, Olmos escribió una Lamentación a tres voces, otra a dúo y cuatro Lamentaciones a solo de Tiple ${ }^{71}$ entre las cuales consta la única transcripción que hemos encontrado en todo su repertorio; una Lamentación original de Joaquín Serra escrita para Alto solista que Olmos, efectivamente, transcribió para Tiple ${ }^{72}$.

\footnotetext{
70 “'L'herència del segle XVI liderada per Morales, i, potser sobretot, per Victoria, es va transmetre a la següent centúria. No obstant això, ja sabem que la tradició hispànica no va poder abstraure's a les transformacions estilístiques del 1600, de manera que no va tardar a arribar, en paraules de López-Calo, la passió pel barroc. Primerament, es va ampliar la plantilla vocal, però, després, sobretot, es va imposar la predilecció per la melodia. Segons el musicòleg, l’aplicació d'aquest principi estètic a les Lamentacions és l'origen a la nostra geografia de la nova forma citada anteriorment; la Lamentació monòdica de caràcter virtuosístico. Amb tot, no és possible precisar quan i qui introdueix la Lamentació a solo en la nostra cultura musical, ... No obstant, trobarem fora de les fronteres geogràfiques valencianes la primera Lamentació a solo. Segons López-Calo, tenint en compte la data de defunció, el primer autor d'una Lamentació a solo va ser Miguel de Irízar (†1684)..." ["La herencia del siglo XVI liderada por Morales, y, quizás sobre todo, por Victoria, se transmitió a la siguiente centuria. No obstante, sabemos que la tradición hispánica no pudo ignorar las transformaciones estilísticas del 1600, de manera que no tardó en llegar, en palabras de LópezCalo, la pasión por el barroco. Primeramente, se amplió la plantilla vocal, pero, después, sobre todo, se impuso la predilección por la melodía. Según el musicólogo, la aplicación de este principio estético en las Lamentaciones es el origen en nuestra geografía de la nueva forma citada anteriormente; la Lamentación monódica de carácter virtuosístico. Con todo, no es posible precisar cuándo y quién introduce la Lamentación a solo en nuestra cultura musical,... No obstante, la primera Lamentación a solo se compuso fuera de las fronteras geográficas valencianas. Según López-Calo, teniendo en cuenta la fecha de defunción, el primer autor de una Lamentación a solo fue Miguel de Irízar (†1684)...”] (Marzal, 2019, pp. 271 s.).

${ }^{71}$ La Lamentación catalogada en la signatura 22/11 del Archivo de la Catedral de Segorbe es la misma que la que se encuentra en la 152/11 del Archivo de la Catedral Metropolitana de Valencia. No obstante, los manuscritos presentan algunas diferencias ciertamente significativas en cuanto a la instrumentación. Cfr. Marzal, 2013, pp. 1130-1141 con 1181-1202. Vid. Marzal, 2019, pp. 324-341 y 402-405.

72 (ACS): PM 22/10. Vid. Marzal, 2013, pp. 1107-1129; Marzal, 2019, pp. 390-402 y 632-635.
} 
Sin embargo, es en su producción paralitúrgica donde el maestro Olmos Claver manifiesta plenamente su lenguaje policoral. Casi todos sus villancicos litúrgicos están escritos para doble coro con las masas corales articuladas asimismo entre cinco y ocho voces. En el marco al que nos referimos, el uso de un coro solista o favorito y de otro di ripieno es uno de sus elementos identificativos. De hecho, escribió quince villancicos a ocho voces. No obstante, también compuso un villancico litúrgico para cuarteto vocal, otro para trio, además del que escribió para la oposición al magisterio de la Catedral de Segorbe del que, como ya hemos anticipado, solo nos ha llegado la parte de Tiple solista. Asimismo, en esta misma línea de sonoridades contenidas encontraremos también que el "Quatro" está escrito para cuarteto vocal mientras que los "Misterios" y el Aria a la Trinidad para dos voces solistas.

El análisis del lenguaje policoral de Olmos permite verificar el uso de la antifonalidad. El compositor combina alternativamente la polifonía con la homofonía entre las dos masas corales. Generalmente, el coro solista canta polifónicamente mientras que el segundo coro responde de forma homofónica. Asimismo, conviene resaltar el uso del contrapunto, en entramado e imitación, en los fragmentos polifónicos donde, además, el músico alterna las voces solistas enriqueciendo así el lenguaje "solista" del primer coro contrastante respecto al "tutti" del segundo. En la música de Olmos, no obstante, el emblemático "solo" del siglo XVIII no está restringido a las composiciones policorales, porque, nuestro músico es autor de un notorio corpus musical para solistas donde encontraremos, por ejemplo, el "Quatro" o los "Misterios", pero, sobre todo, como ya hemos dicho, las Lamentaciones.

Las estructuras formales de las composiciones musicales de Vicente Olmos están siempre determinadas por los textos poéticos. En el caso de la música escrita para la más estricta liturgia, los textos proceden lógicamente de la Biblia; principalmente del Libro de los Salmos y también del Libro de las Lamentaciones. Del primero, el Libro de los Salmos, el maestro Olmos musicalizó los Salmos números 50, 69, 109, 111 y 116. Quizás merece la pena resaltar que el número 50 es el conocido por "Miserere" cuyo texto utilizó en dos composiciones conservadas respectivamente en los archivos de las Catedrales de Valencia ${ }^{73}$ y de Segorbe ${ }^{74}$. En cuanto al Libro de las Lamentaciones, Vicente Olmos tomó para su música los textos del primer y del tercer poema, de manera que, encontraremos los manuscritos de estas composiciones asimismo repartidos entre los dos archivos citados. En términos generales, todos los textos utilizados por el maestro Olmos Claver responden estructuralmente a estrofas de varios versículos articulados en hemistiquios. Así, Olmos escribió frases y períodos musicales diferenciados para cada versículo, sin relación temática y o motívica, sin que ello comporte ninguna deficiencia en cuanto a la homogeneidad de las composiciones.

Por otra parte, desconocemos los autores de los textos empleados en su música paralitúrgica. Seguramente, él mismo debió escribir algunos de ellos porque, de hecho, era frecuente que así se les exigiera a los maestros de capilla. En todo caso, la estructura formal

\footnotetext{
73 (ACV): PM 152/8.

74 (ACS): PM 22/4. 
de estos textos responde asimismo a una organización versicular que Olmos musicalizó no obstante con mayor flexibilidad. Con todo, encontraremos diversas fórmulas estructurales en el género que más cultivó; el villancico litúrgico. En sus villancicos de dos movimientos, o bien, de dos partes significativamente diferenciadas, el maestro Olmos trabajó con el patrón formal más tradicional; "Estribillo-Coplas". Asimismo, también compuso algunos villancicos siguiendo el modelo ternario; "Introducción-Estribillo-Coplas". Sin embargo, es importante señalar que Olmos también escribió con el modelo de cuatro movimientos, tipología quizás más característica de la producción del siglo XVIII; "IntroducciónEstribillo-Recitado-Aria". Según nos dice el musicólogo Jordi Rifé, La consolidació de l'ús de l'ària i el recitat es donen a València per mà de Josep Pradas (Rifé, 1999, p. 83). Por tanto, merece la pena recordar que Pradas fue cronológicamente el primero de los tres maestros que instruyeron a Vicente Olmos Claver.

Otro aspecto que merece ser comentado es la funcionalidad de los villancicos litúrgicos de Vicente Olmos Claver. Nuestro maestro de capilla escribió principalmente villancicos al "Nacimiento", es decir, para la Navidad. Compuso concretamente veinticuatro villancicos al "Nacimiento" que actualmente guarda en nueve signaturas el archivo de la Catedral de Segorbe ${ }^{75}$; cinco de estas signaturas contienen series de cuatro villancicos para la Kalenda, es decir, la noche de Navidad ${ }^{76}$. Además, Vicente Olmos compuso cinco villancicos al "Santísimo Sacramento" para la festividad del Corpus Christi. Asimismo, dedicó un villancico a "María Santísima", escribió el villancico para la "Professión de Sor Maria Joachina" y es autor de otro villancico sin dedicatoria del que solo se han conservado las partes de Tiple solo en $10^{\circ}$ coro, a 5 y la de Acompañamiento Continuo $^{77}$. El catálogo de villancicos litúrgicos compuestos por Vicente Olmos, que, como hemos dicho anteriormente, asciende a treinta y tres y se conserva íntegramente en el archivo de la Catedral de Segorbe, se completa con el villancico que escribió para las oposiciones de acceso al magisterio de dicha Catedral ${ }^{78}$. Para finalizar el análisis funcional, debemos señalar que Vicente Olmos escribió en 1774 un Quatro ${ }^{79}$, tipología asimismo paralitúrgica cercana al villancico, para dar las Pasquas a los Señores Canónigos. En cuanto a los "Misterios" ${ }^{80}$ de Vicente Olmos Claver, cabe decir que su contenido descriptivo diferencia significativamente la composición del resto del repertorio paralitúrgico.

El análisis de la música de Vicente Olmos Claver también permite constatar que el músico instrumentaba con tres familias instrumentales; viento, cuerda e instrumentos de teclado. Entre la familia instrumental de viento podemos diferenciar asimismo el uso de instrumentos de viento madera y también de viento metal. En el viento madera, el maestro Olmos usa principalmente el oboe tanto en la música litúrgica como en la paralitúrgica. Además, instrumenta puntualmente para dos oboes como, por ejemplo, en la Misa. Menos frecuente es, sin embargo, el uso de la flauta travesera cuya función es a menudo opcional

\footnotetext{
75 (ACS): PM 22/14, PM 22/15, PM 22/17, PM 22/18, PM 22/19, PM 22/21, PM 22/23, PM 22/26, PM $22 / 30$.

76 (ACS): PM 22/19, PM 22/21, PM 22/23, PM 22/26 y PM 22/30.

77 (ACS): PM 22/29.

78 (ACS): PM 22/13.

79 (ACS): PM 22/16.

80 (ACS): PM 29/18.
} 
para sustituir al oboe o, puntualmente, al violón. No obstante, merece la pena señalar que Olmos escribió en la Misa una parte compartida para oboe y flauta, y, que, en una de las Lamentaciones lo hizo para flauta travesera para quando no haya Violon. Finalmente, el Bajón completa la familia de los instrumentos de viento madera utilizados por Vicente Olmos. Antecedente del fagot, el Bajón cumplía generalmente la función de doblar el acompañamiento continuo. Vicente Olmos escribió una parte específica para este instrumento, concretamente, en la Lamentación a dúo que conserva el archivo de la Catedral Metropolitana de Valencia ${ }^{81}$. Por otra parte, en lo que respecta al uso de los instrumentos de viento metal, el maestro Olmos instrumenta con trompas que, ocasionalmente, alternan con Clarines. Así, encontramos manuscritos para dos trompas en varios de los géneros que el músico cultivó. Están siempre escritas en clave de Fa en cuarta línea y cumplen generalmente funciones armónicas. Curiosamente, en uno de los Salmos de Vicente Olmos consta una referencia al sistema medieval de solmización de Guido d'Arezzo; Trompas qe templadas por Alamirre ${ }^{82}$.

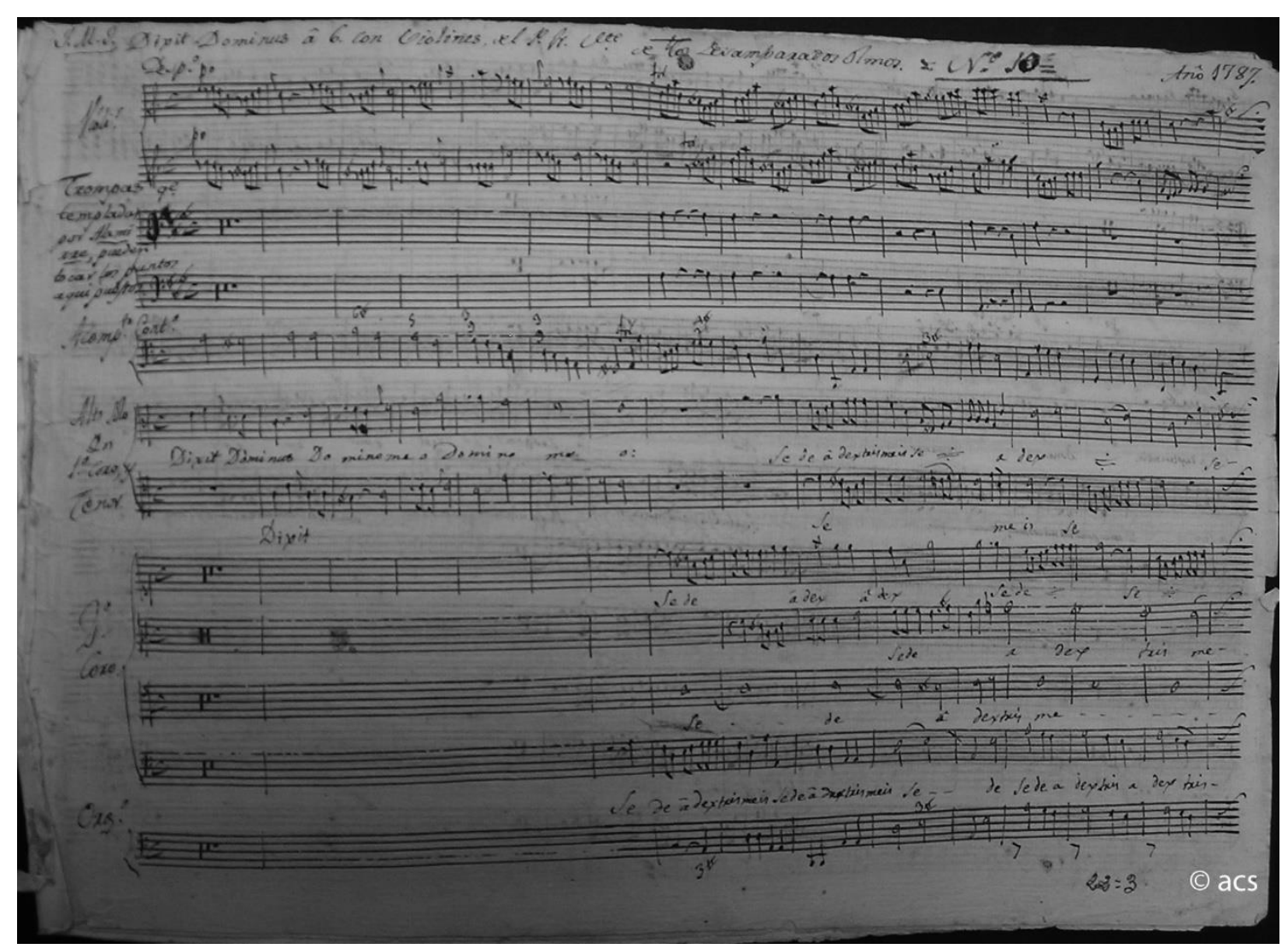

Fig. 2. Dixit Dominus â 6. (ACS): PM 22/3. Partitura, (f. 1 r.).

[Margen superior izquierdo: Trompas qe templadas por Alamirre,].

81 (ACV): PM 152/10.
82 (ACS): PM 22/3. 
Por lo que se refiere a la familia de los instrumentos de cuerda, encontraremos en la música de Vicente Olmos el violín y el violón. En el caso del violín, Olmos utiliza dos violines, tanto en su producción litúrgica como en los villancicos, cumpliendo principalmente funciones melódicas. Así, consta la instrumentación con dos violines en el Magnificat, en el Verso, en la Misa, en tres Salmos ${ }^{83}$, en una Lamentación ${ }^{84}$ y en la mayor parte de los villancicos. Contrariamente, el uso del violón es mucho menos frecuente. De hecho, solo existe una parte específica en una de las Lamentaciones con obligado Violon ${ }^{85}$ que aparece duplicada para violoncelo en el archivo de la Catedral Metropolitana de Valencia ${ }^{86}$. No obstante, conviene señalar que la función principal del violón en las capillas musicales del XVIII era, similarmente al Bajón, proporcionar soporte rítmico y armónico al acompañamiento continuo.

En cuanto a los instrumentos de teclado, es indispensable remarcar el uso generalizado del "Acompañamiento continuo" en prácticamente toda la producción musical de Vicente Olmos Claver. En sus manuscritos consta la terminología Acompañamiento continuo o bien, algunas veces, Bajo continuo. Con excepciones muy puntuales, en el acompañamiento continuo de Vicente Olmos predomina el uso del cifrado de estilo francés determinando la armonía de la composición. Siguiendo la praxis musical de la época, el continuo era interpretado por algún instrumento polifónico y doblado a la vez con otros instrumentos. Así, en el caso de Vicente Olmos ya hemos comprobado el uso incluso específico del bajón y del violón en las capillas musicales de las Catedrales de Segorbe y de Valencia. Con todo, el uso de instrumental polifónico era absolutamente imprescindible. De hecho, en los manuscritos de Vicente Olmos constan también partes específicas escritas para el clavicémbalo ${ }^{87}$.

Paralelamente, es indispensable citar el uso del órgano en la música de Vicente Olmos. De hecho, no podía ser de otra manera dado que este instrumento forma parte del repertorio sacro desde tiempos inmemoriales. No obstante, en la producción de Olmos su uso está condicionado asimismo por la policoralidad. El maestro Olmos lo introdujo en algunas de sus composiciones exclusivamente para proporcionar soporte armónico al segundo coro o coro di ripieno. Así, este instrumento consta específicamente en la mayor parte de las partituras de Olmos escritas para más de cuatro voces. Asimismo, vale la pena señalar que las partes manuscritas de órgano tienen secciones asignadas a los "clarines", circunstancia que denota el uso de los registros del instrumento con la intención de enriquecer tímbricamente la sonoridad de las composiciones.

En cuanto a la armonía, debemos señalar que Olmos trabaja con una armonía tonal. Aunque algunas de sus obras conservan cierto carácter modal, los manuscritos del maestro Olmos cuentan con alteraciones en la armadura, de manera que, pensaba más en la tonalidad que en los usos modales tradicionales de la Iglesia. Con todo, Olmos compone con una armonía triádica en un sistema tonal que se implantó con dos modos; mayor y

83 (ACS): PM 22/3, PM 22/ 5 y PM 22/7.

84 (ACS): PM 22/10.

85 (ACS): PM 22/11.

86 (ACV): PM 152/11.

87 (ACS): PM 22/11. 
menor. Por otra parte, nuestro maestro dibuja su melodía por grados conjuntos abarcando amplias tesituras en las voces, con tratamientos, sobre todo, ornamentados y también silábicos. Asimismo, es indispensable señalar el uso de extensos melismas, sobre todo en la Lamentaciones, situándolas en un alto nivel de complejidad técnica a la altura estilística del italianismo del siglo XVIII ${ }^{88}$.

En las composiciones de Vicente Olmos no solo encontraremos diversos ritmos melódicos, sino, que, a consecuencia de las complejas estructuras texturales se generan a menudo fragmentos con ritmo armónico. Por otra parte, el músico utiliza la subdivisión binaria y ternaria con compases de dos, tres y cuatro tiempos reflejados con las grafías actuales. Solo hemos encontrado una grafía actualmente en desuso ${ }^{89} ; C 6 / 4$. En cuanto a la agógica, Olmos utiliza términos como Andante o Allegro que, de hecho, han llegado hasta nuestros días. Sin embargo, también constan otros movimientos agógicos como, por ejemplo, Medio Ayre, que, de raíces renacentistas instaurado en el barroco temprano, terminó desapareciendo de nuestro lenguaje musical. Con todo, Olmos era consciente de la función expresiva que el movimiento agógico ejerce en la música. Así, hemos comprobado diferentes usos de la agógica en función de los distintos géneros compositivos. En cuanto a la dinámica, merece la pena resaltar asimismo el uso diferenciado de la terminología según se trate de partes vocales o bien instrumentales. Efectivamente, en los manuscritos de las partes vocales constan términos propios del llamado barroco hispánico; Voz y Eco. Mientras, para los instrumentos usa términos que han perdurado hasta nuestros días; forte y piano. El significado en ambos casos es equivalente a efectos de gradación sonora, es decir, mayor o menor intensidad respectivamente del aparato vocal o instrumental. No obstante, resulta quizás más interesante remarcar que el maestro Olmos usaba asimismo la dinámica como herramienta de expresión. Por ejemplo, existen fragmentos donde nuestro maestro de capilla exige intensidad sonora a la voz a "solo" y simultáneamente "piano" a los instrumentos.

Para concluir, solo nos gustaría señalar que el maestro Vicente Olmos Claver es autor de una amplia producción musical realizada en y para la Iglesia que detallamos seguidamente en las Tablas de nuestro Anexo. Enmarcada en un período convulso de nuestra historia, su aportación musical fue llevada a cabo en distintas etapas biográficas y de creación. Cultivó distintos géneros y variadas tipologías compositivas dentro de un panorama musical caracterizado por las tendencias de origen italiano. Por nuestra parte, solo nos queda expresar nuestra satisfacción por haber podido llevar a cabo esta investigación que rescata del olvido a uno de nuestros autores. Esperamos que las generaciones futuras puedan disfrutar con su música.

\footnotetext{
${ }^{88}$ E. g.: (ACS): PM 22/10.
}

89 (ACS): PM 22/19. 


\section{ÁNGEL MARZAL RAGA}

\section{ANEXO}

En este anexo presentamos cinco tablas que nos permitirán consultar distintos aspectos de la obra creativa del maestro Vicente Olmos Claver; cronología, archivos, géneros, períodos creativos y autógrafos.

\section{TABLA 1. CRONOLOGÍA}

La siguiente tabla especifica la cronología de la obra creativa de Vicente Olmos.

\begin{tabular}{|c|c|}
\hline Año & Composición \\
\hline 1763 & $\begin{array}{l}\text { Dixit Dominus }\left(1^{\circ} \text { tono) } \hat{a} 8^{\circ} . \text { [ACS: PM 22/1]. }\right. \\
\text { Psalmo Beatus vir (2ºno) } \hat{a} 8 . \text { [ACS: PM 22/6]. }\end{array}$ \\
\hline 1765 & Missa â 4. y â 8. con Violines, Oboeses, y Trompas. [ACS: PM 22/12]. \\
\hline 1768 & $\begin{array}{l}\text { Villancico â 6. Con Violines y Clarines para la Profesión de Sor Maria } \\
\text { Joachina. [ACS: PM 22/27]. }\end{array}$ \\
\hline 1770 & $\begin{array}{l}\text { Beatus vir â 6. [ACS: Sig. 22/5]. } \\
\text { Laudate Dominum â 5. [ACS: PM 22/7]. }\end{array}$ \\
\hline 1772 & $\begin{array}{l}\text { Domine ad adjuvandum me. â 6. [ACS: PM 22/2]. } \\
\text { Miserere à 8. [ACS: PM 22/4]. } \\
\text { No se me oscurezca el sol. [ACS: PM 22/13]. } \\
\text { Dile Pascual a Isabel. [ACS: PM 22/14]. } \\
\text { Esta noche un amor nace. [ACS: PM 22/15]. }\end{array}$ \\
\hline 1773 & Por besar la mano al Niño. [ACS: PM 22/17]. \\
\hline 1774 & $\begin{array}{l}\text { Quatro para dar las Pascuas los Infantillos, a los Señores obispo, y Canónigos. [ACS: } \\
\text { PM 22/16]. } \\
\text { Ola Hau? Ha del mundo? [ACS: PM 22/18]. }\end{array}$ \\
\hline 1775 & $\begin{array}{l}\text { Completas â 6. [ACS: PM 22/9]. } \\
\text { Villancicos del Nacimiento del Señor. ;Ah; de la lóbrega estancia. Rompa el mar su } \\
\text { espaciosa esfera. Pero el Niño con ojos. jObj, qué gozosas caminan. [ACS: PM 22/19]. }\end{array}$ \\
\hline 1776 & $\begin{array}{l}\text { Lamentación Sola } 3^{a} \text { para la tarde del Jueves Santo. [ACS: PM 22/10]. } \\
\text { A la escuela venid presurosos. ;Ayj, qué fineza. [ACS: PM 22/20]. } \\
\text { Mortales hijos de Adán. Venid que en la ley de gracia. Cielo, Sol, Luna y estrellas. Al } \\
\text { portal, zagalitos. [ACS: PM 22/21]. }\end{array}$ \\
\hline 1778 & $\begin{array}{l}\text { Lamentación } 3^{a} \text { para el Jueves por la tarde. [ACV: PM 152/11]. } \\
\text { Lamentación } 3^{a} \text { para el Jueves Santo por la tarde. [ACS: PM 22/11]. } \\
\text { Del Imperio de las luces. [ACS: PM 22/22]. } \\
\text { Resuenen armoniosos los clarines. Pues ya en brazos de María. Supuesto que cuando } \\
\text { naces. Que los prados y montes. [ACS: PM 22/23]. }\end{array}$ \\
\hline 1779 & $\begin{array}{l}\text { Aria â Duo con Violines y âcompañamiento. [ACS: PM 98/23]. } \\
\text { Matutinas aves. [ACS: PM 22/24]. } \\
\text { De Pan los accidentes. [ACS: PM 22/25]. }\end{array}$ \\
\hline
\end{tabular}


El MAESTRO dE CAPILla VICENTE OLMOS ClAVER Y SU APORTACIÓN A LA MÚSICA RELIGIOSA ESPAÑOLA DEL SIGLO XVIII

\begin{tabular}{|c|c|}
\hline & $\begin{array}{l}\text { Alegría, mortales- Aquel primitivo incendio- iAyi, que está dormido-Por Dios que no es } \\
\text { mala. [ACS: PM 22/26]. }\end{array}$ \\
\hline 1780 & $\begin{array}{l}\text { Desde que Adán cometió el desordenado exceso. Qué tempestad amenaza. Escuchad, } \\
\text { pastores. Entra contenta. [ACS: PM 22/30]. }\end{array}$ \\
\hline 1787 & Dixit Dominus â 6. [ACS: PM 22/3]. \\
\hline 1788 & Miserere â 4. Llano. [ACV: PM 152/8]. \\
\hline 1789 & Lamentación â Solo. $2^{a}$ del Miercoles. [ACV: PM 152/9]. \\
\hline 1791 & Magnificat â 6. Con Violines, y Trompas. [ACS: PM 22/8]. \\
\hline 1807 & Lamentación â Duo para el Miercoles $2^{\circ}$. [ACV: PM 152/10]. \\
\hline 1808 & Lamentación â tres. Tercera del Jueves. [ACV: PM 128/3]. \\
\hline Sin fecha & $\begin{array}{l}\text { Misterios á Duo del Mtro. Olmos. [ACS: PM 29/18]. } \\
\text { Villanci.co â } 8 \text { Con Violines, y Clarines. A Maria Santtissima Descarriada la obeja. } \\
\text { [ACS: PM 22/28]. } \\
\text { Tortolilla amorosa. [ACS: PM 22/29]. }\end{array}$ \\
\hline
\end{tabular}

\section{TABLA 2. ARCHIVOS}

La tabla siguiente muestra en qué archivo se conserva cada una de las composiciones de Vicente Olmos Claver; Archivo de la Santa Iglesia Catedral de Segorbe y Archivo de la Catedral Metropolitana de Valencia.

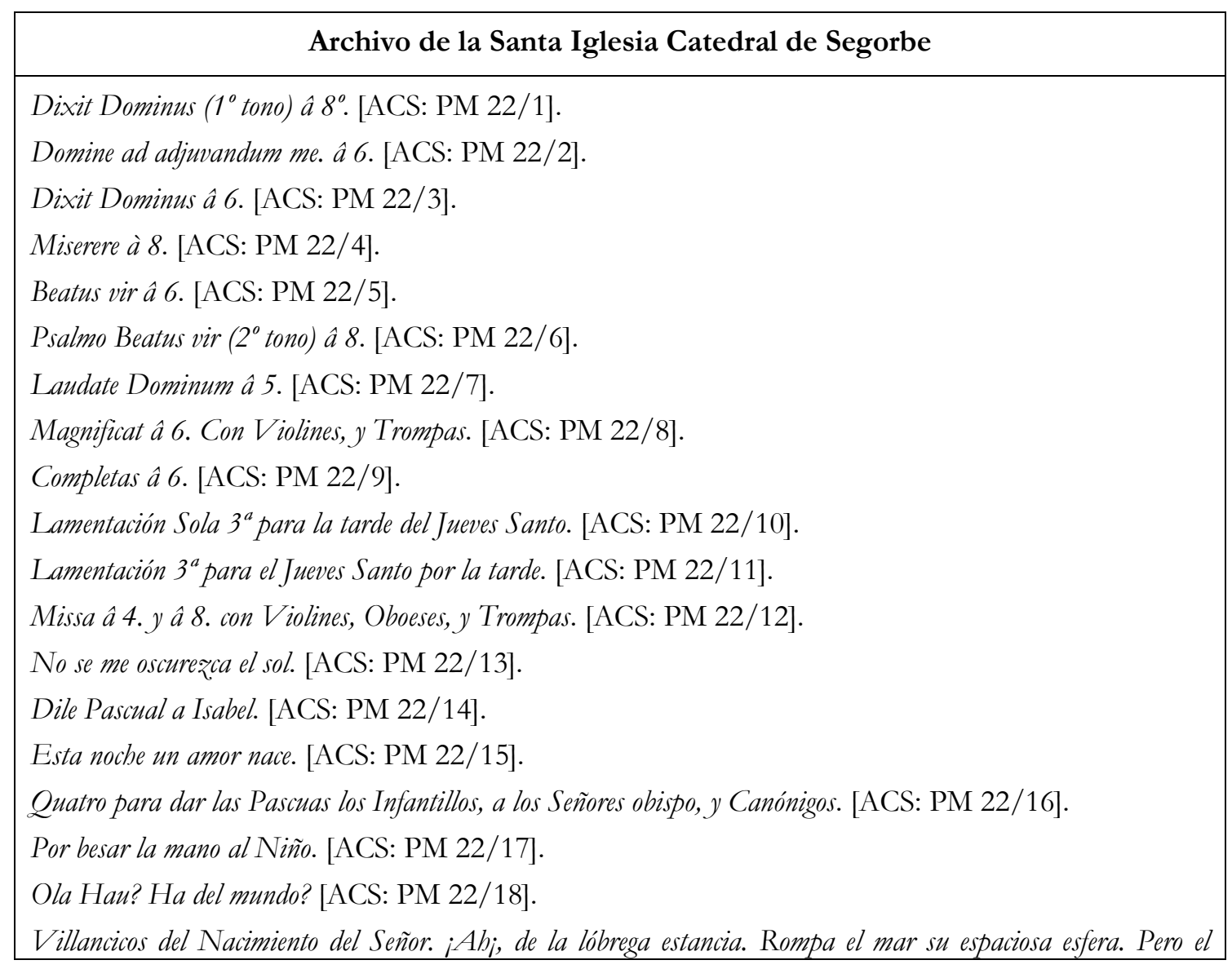




\section{ÁNGEL MARZAL RAGA}

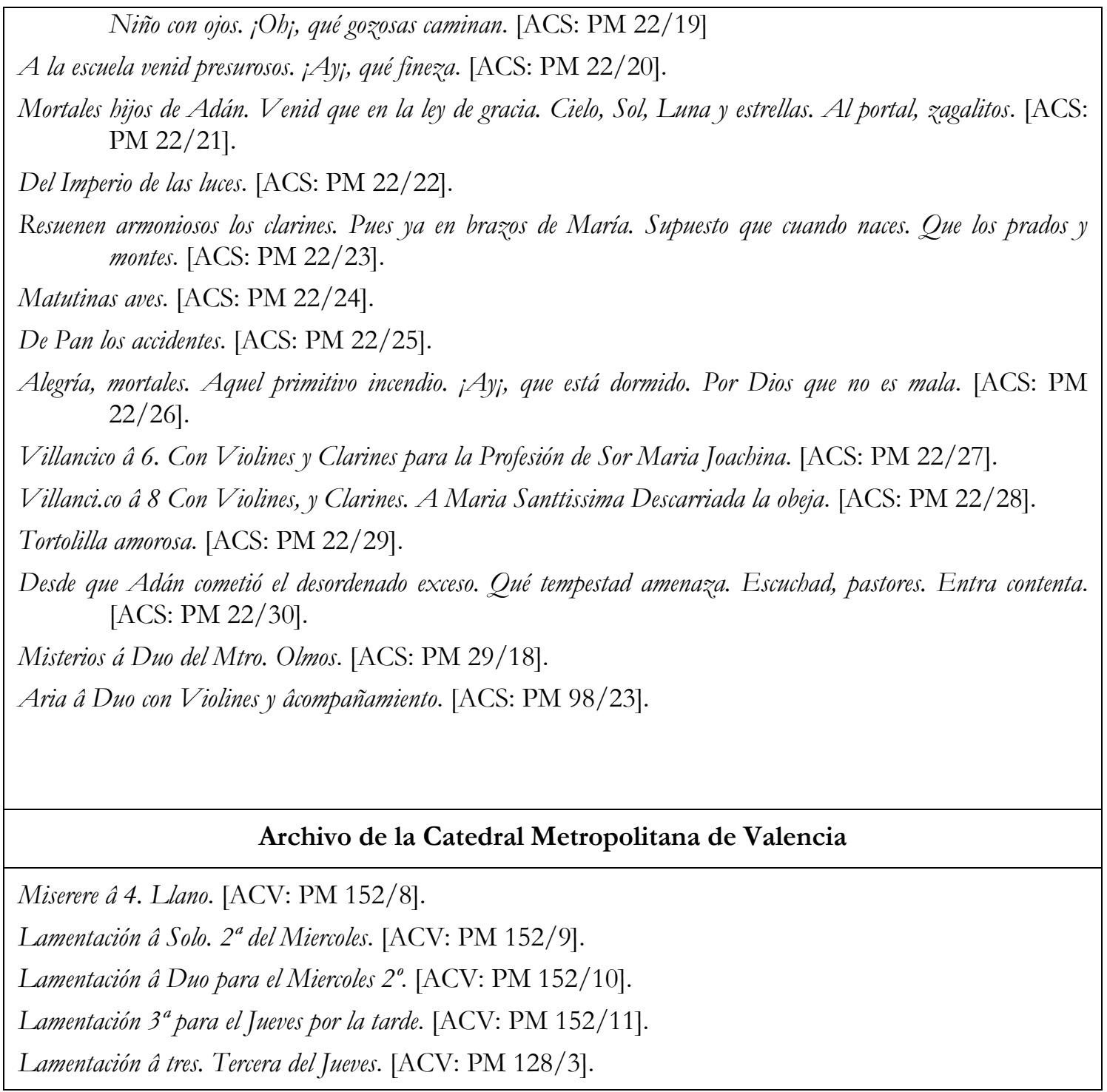

\section{TABLA 3. GÉNEROS}

La siguiente tabla divide la producción musical del maestro en dos grandes bloques; música litúrgica y paralitúrgica.

\section{Obras litúrgicas; Salmos, Lamentaciones, Verso, Misa, Magnificat y Completas}

Dixit Dominus $\left(1^{\circ}\right.$ tono) $\hat{a} 8^{\circ}$. [ACS: PM 22/1].

Domine ad adjuvandum me. â 6. [ACS: PM 22/2].

Dixit Dominus â 6. [ACS: PM 22/3].

Miserere à 8. [ACS: PM 22/4].

Beatus vir â 6. [ACS: PM 22/5].

Psalmo Beatus vir (2ºno) â 8 . [ACS: PM 22/6].

Laudate Dominum â 5. [ACS: PM 22/7].

Magnificat â 6. Con Violines, y Trompas. [ACS: PM 22/8]. 
Completas â 6. [ACS: PM 22/9].

Lamentación Sola $3^{a}$ para la tarde del Jueves Santo. [ACS: PM 22/10].

Lamentación $3^{a}$ para el Jueves Santo por la tarde. [ACS: PM 22/11].

Missa â 4. y â 8. con Violines, Oboeses, y Trompas. [ACS: PM 22/12].

Miserere â 4. Llano. [ACV: PM 152/8].

Lamentación â Solo. $2^{a}$ del Miercoles. [ACV: PM 152/9].

Lamentación â Duo para el Miercoles 2. [ACV: PM 152/10].

Lamentación $3^{a}$ para el Jueves por la tarde. [ACV: PM 152/11].

Lamentación â tres. Tercera del Jueves. [ACV: PM 128/3].

\section{Obras paralitúrgicas; Villancicos litúrgicos, Quatro, Misterios y Aria}

No se me oscurezca el sol. [ACS: PM 22/13].

Dile Pascual a Isabel. [ACS: PM 22/14].

Esta noche un amor nace. [ACS: PM 22/15].

Quatro para dar las Pascuas los Infantillos, a los Señores obispo, y Canónigos. [ACS: PM 22/16].

Por besar la mano al Niño. [ACS: PM 22/17].

Ola Hau? Ha del mundo? [ACS: PM 22/18].

Villancicos del Nacimiento del Señor. ;Ab; de la lóbrega estancia. Rompa el mar su espaciosa esfera. Pero el Niño con ojos. jObj, qué gozosas caminan. [ACS: PM 22/19]

A la escuela venid presurosos. ;Ay; qué fineza. [ACS: PM 22/20].

Mortales hijos de Adán. Venid que en la ley de gracia. Cielo, Sol, Luna y estrellas. A el Portal, Zagalitos. [ACS: PM 22/21].

Del Imperio de las luces. [ACS: PM 22/22].

Resuenen armoniosos los clarines. Pues ya en brazos de María. Supuesto que cuando naces. Que los prados y montes. [ACS: PM 22/23].

Matutinas aves. [ACS: PM 22/24].

De Pan los accidentes. [ACS: PM 22/25].

Alegría, mortales- Aquel primitivo incendio- iAy; que está dormido- Por Dios que no es mala. [ACS: PM 22/26].

Villancico â 6. Con Violines y Clarines para la Profesión de Sor Maria Joachina. [ACS: PM 22/27].

Villanci.co â 8 Con Violines, y Clarines. A Maria Santtissima Descarriada la obeja. [ACS: PM 22/28].

Tortolilla amorosa. [ACS: PM 22/29].

Desde que Adán cometio el desordenado exceso. Qué tempestad amenaza. Escuchad, pastores. Entra contenta. [ACS: PM 22/30].

Misterios á Duo del Mtro. Olmos. [ACS: PM 29/18].

Aria â Duo con Violines y âcompañamiento. [ACS: PM 98/23]. 


\section{TABLA 4. PERÍODOS CREATIVOS}

La biografía de Vicente Olmos Claver se puede estructurar en cuatro etapas diferenciadas de creación musical; formación en la Catedral Metropolitana de Valencia, maestro de la capilla de música del Palacio Real de Valencia, maestro de la capilla de música de la Santa Iglesia Catedral de Segorbe y monje Jerónimo en el monasterio de Nuestra Señora de la Murta de Alzira.

\begin{tabular}{|c|c|}
\hline Período & Composiciones \\
\hline $\begin{array}{c}\text { Formación en la Catedral } \\
\text { Metropolitana de } \\
\text { Valencia; 1754- } 1768\end{array}$ & $\begin{array}{l}\text { Dixit Dominus }\left(1^{\circ} \text { tono) } \hat{a} 8^{\circ} \text {. [ACS: PM 22/1]. }\right. \\
\text { Psalmo Beatus vir (2 } 2^{\circ} \text { tono) â } 8 \text {. [ACS: PM 22/6]. } \\
\text { Missa â 4. y â 8. con Violines, Oboeses, y Trompas. [ACS: PM 22/12]. }\end{array}$ \\
\hline $\begin{array}{c}\text { Maestro de capilla del } \\
\text { Palacio Real de Valencia; } \\
\text { 1768- } 1772\end{array}$ & $\begin{array}{l}\text { Villancico â 6. Con Violines y Clarines para la Profesión de Sor Maria } \\
\text { Joachina. [ACS: PM 22/27]. } \\
\text { Beatus vir â 6. [ACS: PM 22/5]. } \\
\text { Laudate Dominum â 5. [ACS: PM 22/7]. }\end{array}$ \\
\hline $\begin{array}{l}\text { Maestro de capilla de la } \\
\text { Santa Iglesia Catedral de } \\
\text { Segorbe; } 1772-1779\end{array}$ & $\begin{array}{l}\text { Domine ad adjuvandum me. â 6. [ACS: PM 22/2]. } \\
\text { Miserere à 8. [ACS: PM 22/4]. } \\
\text { No se me oscurezca el sol. [ACS: PM 22/13]. } \\
\text { Dile Pascual a Isabel. [ACS: PM 22/14]. } \\
\text { Esta noche un amor nace. [ACS: PM 22/15]. } \\
\text { Por besar la mano al Niño. [ACS: PM 22/17]. } \\
\text { Quatro para dar las Pascuas los Infantillos, a los Señores obispo, y Canónigos. } \\
\quad \text { [ACS: PM 22/16]. } \\
\text { Ola Hau? Ha del mundo? [ACS: PM 22/18]. } \\
\text { Completas â 6. [ACS: PM 22/9]. } \\
\text { Villancicos del Nacimiento del Señor. jAb;, de la lóbrega estancia. Rompa el } \\
\quad \text { mar su espaciosa esfera. Pero el Niño con ojos. ;Ob;, qué gozosas } \\
\quad \text { caminan. [ACS: PM 22/19] } \\
\text { Lamentación Sola 3a para la tarde del Jueves Santo. [ACS: PM 22/10]. } \\
\text { A la escuela venid presurosos. iyj; qué fineza. [ACS: PM 22/20]. } \\
\text { Mortales hijos de Adán. Venid que en la ley de gracia. Cielo, Sol, Luna y } \\
\quad \text { estrellas. Alportal, ragalitos. [ACS: PM 22/21]. } \\
\text { Lamentación } 3^{a} \text { para el Jueves por la tarde. [ACV: PM 152/11]. } \\
\text { Lamentación } 3^{a} \text { para el Jueves Santo por la tarde. [ACS: PM 22/11]. } \\
\text { Del Imperio de las luces. [ACS: PM 22/22]. } \\
\text { Resuenen armoniosos los clarines. Pues ya en brazos de María. Supuesto que } \\
\quad \text { cuando naces. Que los pradosy montes. [ACS: PM 22/23]. } \\
\text { Aria â Duo con Violinesy âcompañamiento. [ACS: PM 98/23]. } \\
\text { Matutinas aves. [ACS: PM 22/24]. } \\
\text { De Pan los accidentes. [ACS: PM 22/25]. } \\
\text { Alegría, mortales- Aquel primitivo incendio- ;Ay;, que está dormido- Por Dios }\end{array}$ \\
\hline
\end{tabular}


El MAESTRO DE CAPILla ViCENTE OlMOS ClAVER Y SU APORTACIÓN A LA

MÚSICA RELIGIOSA ESPAÑOLA DEL SIGLO XVIII

\begin{tabular}{|c|c|}
\hline & $\begin{array}{l}\text { que no es mala. [ACS: PM 22/26]. } \\
\text { Desde que Adán cometió el desordenado exceso. Qué tempestad amenaza. } \\
\text { Escuchad, pastores. Entra contenta. [ACS: PM 22/30]. }\end{array}$ \\
\hline $\begin{array}{l}\text { Monje del monasterio de } \\
\text { Nuestra Señora de la Murta } \\
\text { d'Alzira; 1779- } 1808\end{array}$ & $\begin{array}{l}\text { Dixit Dominus â 6. [ACS: PM 22/3]. } \\
\text { Miserere â 4. Llano. [ACV: PM 152/8]. } \\
\text { Lamentación â Solo. } 2^{a} \text { del Miercoles. [ACV: PM 152/9]. } \\
\text { Magnificat â 6. Con Violines, y Trompas. [ACS: PM 22/8]. } \\
\text { Lamentación â Duo para el Miercoles 2. [ACV: PM 152/10]. } \\
\text { Lamentación â tres. Tercera del Jueves. [ACV: PM 128/3]. }\end{array}$ \\
\hline Sin fecha & $\begin{array}{l}\text { Misterios á Duo del Mtro. Olmos. [ACS: PM 29/18]. } \\
\text { Villanci.co â } 8 \text { Con Violines, y Clarines. A Maria Santtissima Descarriada } \\
\quad \text { la obeja. [ACS: PM 22/28]. } \\
\text { Tortolilla amorosa. [ACS: PM 22/29]. }\end{array}$ \\
\hline
\end{tabular}

\section{TABLA 5. AUTÓGRAFOS}

La mayor parte de los manuscritos del maestro están firmados como Mosén Vicente Olmos. Sin embargo, existe también una parte significativa de su obra firmada con el nombre monástico Fray Vicente de los Desamparados Olmos.

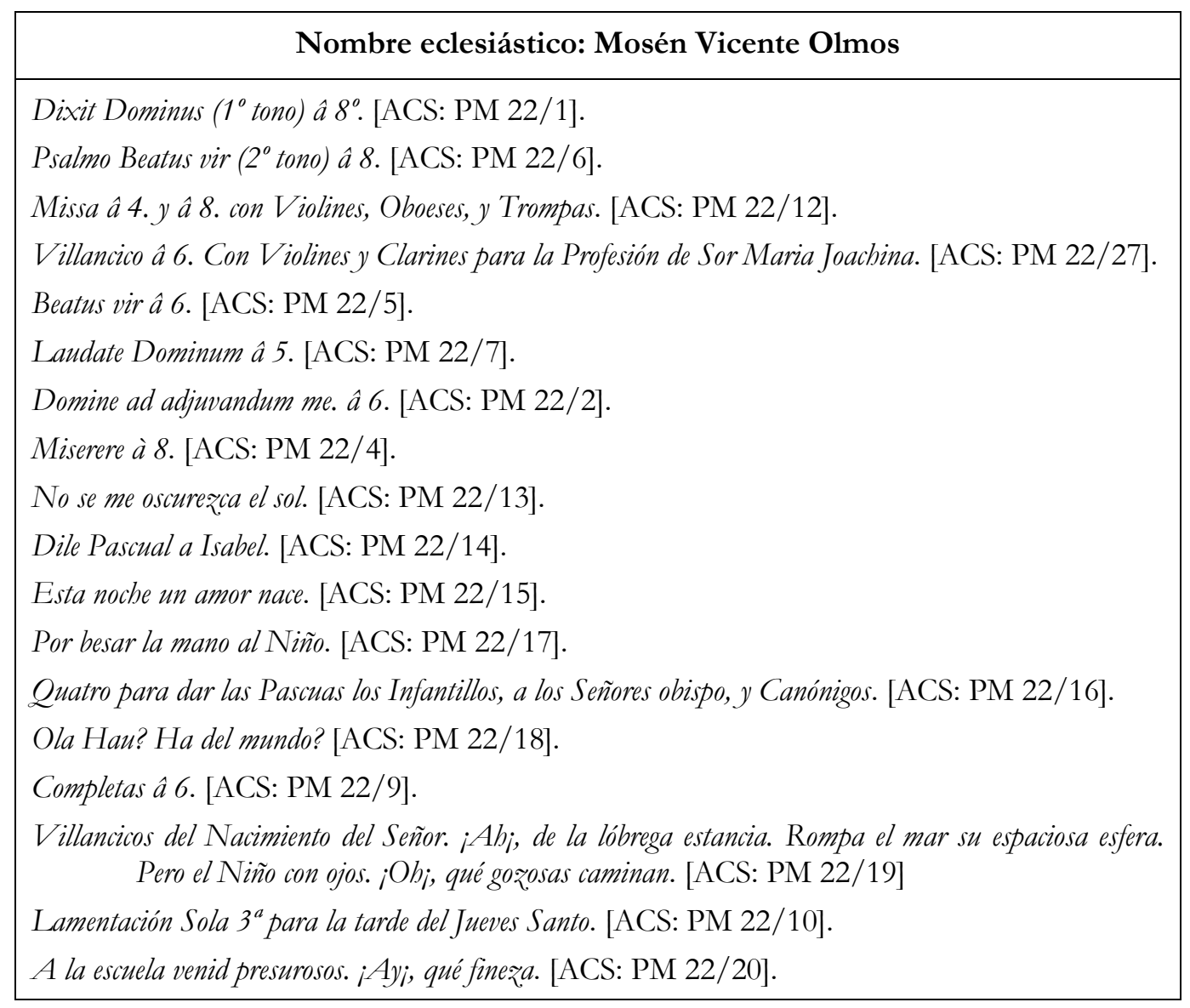




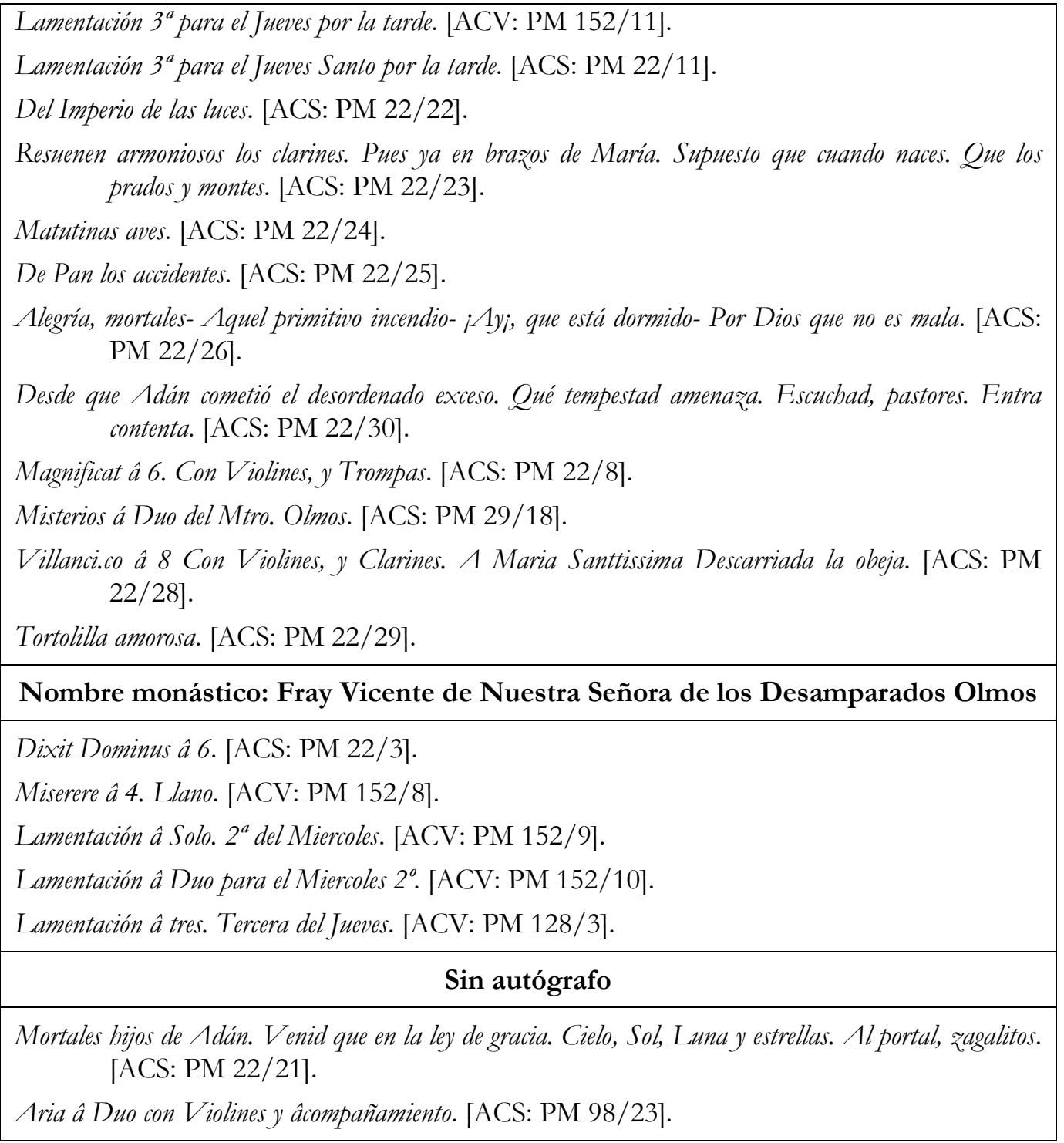

\section{DOCUMENTACIÓN}

Archivo de la Catedral Metropolitana de Valencia (ACV): 2926 Oposiciones, A Beneficio con carga especial 463-15.

Archivo de la Catedral Metropolitana de Valencia (ACV): 2796 Música y músicos, Volumen 1631. Libro de salarios y nombramiento de Capellanes cantores y de músicos de 1605 a 1810.

Archivo de la Catedral Metropolitana de Valencia (ACV): 590. Bolsa de coro. Distribuciones o jornadas de coro desde 1750 a 1755.5537. 


\section{El MAESTRO DE CAPILLA VICENTE OLMOS ClAVER Y SU APORTACIÓN A LA}

MÚSICA RELIGIOSA ESPAÑOLA DEL SIGLO XVIII

Archivo de la Catedral Metropolitana de Valencia (ACV): 3335 Protocolos del cabildo 1768 $2^{\mathrm{a}}$, Notario Pere Rodrigo.

Archivo de la Catedral Metropolitana de Valencia (ACV): 1278 Deliberaciones capitulares, 302, Verbales 9 stbre 1709 a 1775.

Archivo de la Catedral Metropolitana de Valencia (ACV): 3340 Protocolos del cabildo 1771 $1^{\text {a }}$, Notario Pere Rodrigo.

Archivo del Colegio del Patriarca de Valencia (ACPV): Protocolo n ${ }^{\circ}$ 350, (f. 26 v. a 31), 23 de enero de 1769, notario Juan Antonio Espada.

Archivo de la Catedral Metropolitana de Valencia (ACV): 2796 Música y músicos, 693. Llibre de Beneficiats i Cantors de la Seu de Valencia.

Archivo Diocesano de Valencia (ADV): 525/4. Libro de memorias, y antiguedades, y particulares deliberaciones de la Cathedral Yglesia de la presente Ciudad de Segorbe, hecho por su muy Ille. Cabildo, y empieza en el presente año 1754.

Archivo de la Santa-Iglesia Catedral de Segorbe (ACS): 597, Libro de actas capitulares, 17781788.

Archivo del Reino de Valencia (ARV): Sección Clero, Libro no 4163. Libre de censales, rentas, posesiones y emolumentos que poseía el Monasterio de la Murta.

Archivo del Reino de Valencia (ARV): Sección Clero, Libro de actos capitulares del monasterio de Nuestra Señora de la Murta, 1661-1782, libro núm. 1.117.

Archivo del Reino de Valencia (ARV): Sección Clero, Libro de actos capitulares del monasterio de Nuestra Señora de la Murta, 1782-1835, libro núm. 933.

Biblioteca del Ateneo Mercantil de Valencia (BAMV): Libro de Profesiones del monasterio de Nuestra Señora de la Murta, años 1698-1832.

Archivo del Reino de Valencia (ARV): Sección Clero. Libro no 314. Libro de las cobranzas de las rentas de Valencia y gastos de su sindico procurador desde 1777 en adelante. La Murta.

Archivo del Reino de Valencia (ARV): Sección Clero, Libro n ${ }^{\circ}$ 1003. Libro de gastos del monasterio de $N^{a} S^{a}$ de la Murta, año 1785.

Archivo del Reino de Valencia (ARV): Sección Clero, Libro de comunidades y particulares que responden pensiones de censos y debitorios por la administración de D. Diego Vich y titulos de los 
que responden en la Marina del monasterio de $N^{a}$ Sra de la Murta de Alitira (1777-1827), llibre núm. 962.

Archivo del Reino de Valencia (ARV): Sección Clero. Libro no 2163. Libro de cartas quenta generales y particulares que empieza en 1 de octubre de 1782.

Archivo del Reino de Valencia (ARV): Sección Clero. Libro no 960. Libro de rótulos de los capitulos generales celebrados en el real monasterio de San Bartolomé de Lupiana y de cartas comunes y copias de reales despachos del monasterio de la Murta, (años 1733-1797).

Archivo del Reino de Valencia (ARV): Propiedades Antiguas, legajo no 324. Inventario de los bienes pertenecientes al monasterio suprimido titulado de la Murta. Año 1812.

Archivo del Reino de Valencia (ARV): Sección Clero, Libro de Misas celebradas por su Capellanía, libro núm. 2828.

\section{BIBLIOGRAFÍA}

Arciniega, L., y Serra, A. (2006a). Cort e Palau de Rey. El Palacio Real en época medieval. El Palacio Real de Valencia, Los planos de Manuel Cavallero (1802), pp. 83-90. Valencia: Ayuntamiento de Valencia.

Arciniega, L. y Serra, A. (2006b). El Palacio como escenario de Austrias y Borbones, residencia de virreyes y capitanes generales. El Palacio Real de Valencia, Los planos de Manuel Cavallero (1802), pp. 91-108. Valencia: Ayuntamiento de Valencia.

Alvarez Valladares, C. (2000). Cartas de Profesión. Su valor decorativo y documental. Memoria Ecclesiae, 16, pp. 493-502. Oviedo: Asociación de Archiveros de la Iglesia en España (AAIE).

Artero, J. (1947). Oposiciones al Magisterio de Capilla en España durante el siglo XVIII. Anuario Musical, 2, pp. 191-202. Barcelona: Instituto Español de Musicología, Consejo Superior de Investigaciones Científicas (CSIC).

Climent Barber, J. (1972). Olmos Claver, Vicente. En M. Mas (Dir.). Gran Enciclopedia de la región Valenciana, Tomo 8 (p. 68). Valencia: Mas Ivars Ediciones.

Climent Barber, J. (1979). Fondos Musicales de la Región Valenciana I. Catedral Metropolitana de Valencia. Valencia: Instituto de Musicología “Alfonso el Magnánimo”. 
El maEstro de CAPILla Vicente Olmos ClaVer y SU APORTACión A LA MÚSICA RELIGIOSA ESPAÑOLA DEL SIGLO XVIII

Climent Barber, J. (1984). Fondos Musicales de la Región Valenciana III. Catedral de Segorbe. Segorbe: Publicaciones de la Caja de Ahorros y Monte de Piedad de Segorbe.

Climent Barber, J. (2011). La música en la catedral de Valencia. Valencia: Ayuntamiento de Valencia.

Gallego, A. (1988). La música en tiempos de Carlos III. Ensayo sobre el pensamiento musical ilustrado. Madrid: Alianza Editorial.

Gómez-Ferrer, M., y Bérchez, J. (2003). El Real de Valencia en sus imágenes arquitectónicas. Reales Sitios, 158, pp. 33-47. Madrid.

Lairón Pla, A. J. (2001a). El monasterio de Nuestra Señora de la Murta de Alzira (1552-1835). Estudio Histórico-Diplomático a través de las actas capitulares (Tesis Doctoral), Tomo I. València: Universitat de València-Facultat de Geografia i Història.

Lairón Pla, A. J. (2001b). El monasterio de Nuestra Señora de la Murta de Alzira (1552-1835). Estudio Histórico-Diplomático a través de las actas capitulares (Tesis doctoral), Tomo III (actas capitulares 1661-1782). València: Universitat de València-Facultat de Geografia i Història.

Lairón Pla, A. J. (2001c). El monasterio de Nuestra Señora de la Murta de Alzira (1552-1835). Estudio Histórico-Diplomático a través de las actas capitulares, Tesis doctoral, Tomo IV (actas capitulares 1782-1835). València: Universitat de València-Facultat de Geografía i Història.

López, A. y Olmos, V. S. (1983). Orgues i organistes de Catarroja (València). Cabanilles, 8, pp. 2-32. València: Associació Cabanilles d'Amics de l'Orgue (ACAO).

Marzal Raga, A. (2013). La música de Vicent Olmos i Claver i el seu magisteri a les capelles musicals valencianes del segle XVIII (Tesis Doctoral), Toms I-II. València: Universitat de València-Facultat de Geografia i Història.

Marzal Raga, A. (2019). La música de Vicent Olmos i Claver. Vols. I i II. València: Editorial Piles.

Perpiñán Artíguez, J. (1897). Cronología de los maestros de capilla de la Santa Iglesia Catedral de Segorbe. La música religiosa en España, Año II, 17, pp. 267-271. Madrid: Órgano de la Asociación fundada por el Excmo. Sr. D. José María de Cos. 
Pingarrón Seco, F. (1983). La música al Palau Reial de València al segle XVIII. Cabanilles, 5, pp. 2-32. València: Associació Cabanilles d'Amics de l'Orgue (ACAO).

Rifé i Santaló, J. (1999). La música religiosa en romanç en el barroc. En X. Aviñoa (Dir.). Història de la música Catalana, Valenciana i Balear, vol. 2, Barroc i Classicisme, pp. 53-96. Barcelona: Edicions 62.

RISM (1996). Normas Internacionales para la catalogación de fuentes musicales históricas. (Traducción española y comentarios realizados por: José V. González Valle, Antonio Ezquerro, Nieves Iglesias, C. José Gosálvez y Joana Crespî). Madrid: Arco/Libros S. L.

Rodrigo Valero, J. M. (1990). El clero regular valenciano durante la ocupación francesa de Valencia: reforma religiosa y confiscación de los bienes conventuales. Enero 1812Julio 1813. Saitabi, 40, pp. 67-81, Valencia.

Ruiz de Lihory, J. (1903): Olmos (Vicente). En J. Ruiz de Lihory (Dir.). La música en Valencia. Diccionario Biogräfico y Crítico, (p. 350). Valencia: Establecimiento Tipogràfico Doménech.

Villalmanzo Cameno, J. (1992). La música en la parroquia de los Santos Juanes de Valencia durante el siglo XVIII. Valencia: Conselleria de Cultura, Educació i Ciència. Generalitat Valenciana.

Fecha de recepción: 28/09/2019

Fecha de aceptación: 22/10/2019 